\title{
Unsupervised neural models for country and political risk analysis
}

\author{
Álvaro Herrero ${ }^{\mathrm{a}, 1}$, Emilio Corchado ${ }^{\mathrm{b}, *}$, Alfredo Jiménez ${ }^{\mathrm{c}}$ \\ ${ }^{a}$ Department of Civil Engineering, University of Burgos, C/Francisco de Vitoria s/n, 09006 Burgos, Spain \\ ${ }^{\mathrm{b}}$ Departamento de Informática y Automática, Universidad de Salamanca, Plaza de la Merced s/n, 37008 Salamanca, Spain \\ ${ }^{\mathrm{c}}$ Department of Economics and Business Administration, University of Burgos, C/Parralillos s/n, 09001 Burgos, Spain
}

\section{A R T I C L E I N F O}

\section{Keywords:}

Neural visualization models

Exploratory Projection Pursuit

Unsupervised learning

Country and political risk

Business intelligence

Knowledge extraction

\begin{abstract}
A B S T R A C T
This interdisciplinary research project focuses on relevant applications of Knowledge Discovery and Artificial Neural Networks in order to identify and analyze levels of country, business and political risk. Its main goal is to help business decision-makers understand the dynamics within the emerging market countries in which they operate. Most of the neural models applied in this study are defined within the framework of unsupervised learning. They are based on Exploratory Projection Pursuit, Topology Preserving Maps and Curvilinear Component Analysis. Two interesting real data sets are analyzed to empirically probe the robustness of these models. The first case study describes information from a significant sample of Spanish multinational enterprises (MNEs). It analyses data pertaining to such aspects as decisions over the location of subsidiary enterprises in various regions across the world, the importance accorded to such decisions and the driving forces behind them. Through a projection-based analysis, this study reveals a range of different reasons underlying the internationalization strategies of Spanish MNEs and the different goals they pursue. It may be concluded that projection connectionist techniques are of immense assistance in the process of identifying the internationalization strategies of Spanish MNEs, their underlying motives and the goals they pursue. The second case study covers several risk categories that include task policy, security, and political stability among others, and it tracks the scores of different countries all over the world. Interesting conclusions are drawn from the application of several business intelligence solutions based on neural projection models, which support data analysis in the context of country and political risk analysis.
\end{abstract}

๔ 2011 Elsevier Ltd. All rights reserved.

\section{Introduction}

Corporate decision-makers in a broad range of firms that seek overseas investment opportunities have understood for a number of years that in-depth knowledge of a foreign country's economy is not enough in itself. It is also important to understand the dynamic forces that shape these countries' politics. This is crucial for emerging markets, where market outcomes are influenced at least as much by policies as by economic factors.

A company is considered a multinational enterprise (MNE) whenever it controls activities that generate added value in two or more politically independent geographic areas; in other words, whenever it coordinates and controls subsidiaries in one or more foreign countries (Durán, 2001). To that end, companies can make cross-border acquisitions of existing foreign enterprises, make greenfield investments or commit themselves to an alliance with other multinational enterprises or with a local partner to

\footnotetext{
* Corresponding author. Tel.: +34 616 449888; fax: +34 923294514.

E-mail addresses: ahcosio@ubu.es (Á. Herrero), escorchado@usal.es (E. Corchado), ajimenez@ubu.es (A. Jiménez).

1 Tel.: +3494725 9513; fax: +34947259000.
}

undertake joint activities. Subsidiaries or cross-border business units emerge in this way, which are totally or partially controlled by the parent company.

Internationalization is a decision that enterprises must take with increasing frequency, as competition in many sectors due to globalization, obliges companies to enter international markets in the search for new markets and lower operating costs. Thus, the decision to become a MNE and the challenge of successfully undertaking such a transformation are more relevant than ever.

Furthermore, the structural changes involved in economic development are systematically related to direct investments that are either received or made from a country or a geographic area (Lall, 1996), and at present this direct foreign investment is on the whole made by multinational enterprises; a good enough reason in itself for their study to assume a central role in academic research.

Whereas, in the past, multinational enterprises were large companies with many resources that could be directed at minimizing information gaps, small and medium-sized enterprises, which nowadays also undertake international expansion, cannot afford to expose their limited resources to such high levels of risk (Parks, 1996). Thus, a sound analysis of the risks that are inherent to 
undertaking activities at any particular location is of fundamental importance. Part of this study aims to analyze and establish whether Spanish MNEs take country risk (Avramovic, 1958; Saini \& Bates, 1984) and political risk (Kobrin, 1979) into account, when taking decisions over their location and their presence in external markets. It also aims to determine whether the importance attributed to these variables is modified by the geographic region in which they intend to set up the subsidiary. Moreover, the selection of Spain, a country that over the past 30 years has become a member of the group of developed countries, will allow us to consider the possibility of applying generalizations to other recently developed countries (Galan, Gonzalez-Benito, \& Zuñiga-Vincente, 2007).

Issues surrounding the political risk analysis of Spanish MNEs calls for serious analysis. Such well-known political events as the revolutions in Nicaragua and Iran at the end of the 1970s caught many international banks and MNEs off guard. Other more recent examples include the present-day governments of Bolivia, Venezuela and even Argentina, whose policies have had an important impact on certain Spanish MNEs.

The large financial losses associated with the election of governments calling for greater economic independence from MNEs in those countries clearly demonstrated the importance of political events in host-country environments.

The second case study describes and analyses the status of 158 countries based on ten risk categories which include security, political stability, and financial and tax policy, among others. Country and political risk are complex phenomena that encompass several aspects that can play key roles in investor decision-making processes. Using the same projection techniques as in the first case study, the aim of the second part is to analyze the situation of the countries included in the sample, taking into account the visualized data structure. These visually identified clusters, which comprise countries with a similar degree of institutional and economic development, provide an illustrative worldwide snapshot of risk levels; especially important in the context of a global crisis such as the present one.

The cross-disciplinary field of computational finance relies on computer methods to make trading, hedging and investment decisions, and to manage the risk that is associated with such decisions. Machine learning (ML) is concerned with the design and development of algorithmic techniques that automatically extract rules and identify patterns from data, by applying computational and statistical methods. ML in particular, and Artificial Intelligence techniques in general, have been widely applied to solve different forecasting problems in Economics (Chen \& Huang, 2007; Li \& Sun, 2009). Business Intelligence plays a central role in producing up-to-date information for operative and strategic decision-making (Hannula \& Pirttimäki, 2003). More recently, enterprises have started to apply Business Intelligence systems not only to support strategic decision-making but also a wide variety of other business activities (Elbashir, Collier, \& Davern, 2008).

The identification of patterns that exist across dimensional boundaries in high dimensional datasets is a challenging task. Such patterns may become visible if changes are made to the spatial coordinates; however an a priori decision, as to which parameters will reveal most patterns, requires prior knowledge of the unknown patterns. Some techniques, such as intelligent data analysis (Chen \& Yao, 2008) are aimed at revealing diverse non-trivial features or views of a large amount of data by studying the relations of the objects within a dataset. On the other hand, visualization techniques have been employed to analyze large datasets by providing a visual representation of the information contained in a dataset. These are considered viable approaches in the search for information, which they present on graphic display devices that highlight different characteristics and allow anomalies to be detected by the relevant decisionmakers (Ahlberg \& Shneiderman, 1994).

Within this framework, Artificial Neural Networks (ANNs) are bio-inspired models that can be applied to different problems depending on the neural architecture to be used. They have been proven to successfully perform pattern recognition, information compression, dimensionality reduction, clustering, classification, data visualization, etc. As with other ML paradigms, the most interesting facet of ANN learning is its capacity to generalize after having learned/classified/identified the input patterns. In other words, the network can generalize its results onto a set of test patterns which have not been seen during learning.

This study is based on the application of unsupervised learning within the framework of country, business and political risk. Thus, several ANNs are applied and compared in order to analyze the internal structures of two real-life cases studies. The empirical part of this research seeks to describe the principal characteristics of country and political risk. To do so, two different datasets have been used. The first one (Spanish MNEs dataset) was generated to determine how country and political risk influence the location and the presence in foreign countries of Spanish MNEs, while controlling for the effects of enterprise and company-related variables. As a complementary case study, the Risk Briefing dataset (Risk Briefing, 2009) was chosen, providing a general overview of country and political risk all over the world. These two datasets are comprehensively described in this section.

The study draws interesting conclusions and provides analysis on the use of these methods, which may help us to gain relevant knowledge about the institutional environment of the different possible locations of an investment, as well as valuable up-todate information about the constantly-changing situation once the investment has been made. It is important to highlight that the impact of country and political risk is not only limited to the initial investment period but extends throughout the entire duration of the project.

Cooperative Maximum-Likelihood Hebbian Learning (CMLHL) has been applied to the two case studies. The CMLHL projections were validated through a comparison with those generated by other dimensionality-reduction models such as Principal Component Analysis (PCA) (Hotelling, 1933; Oja, 1989; Pearson, 1901), SOM (Self-Organizing Map) (Kohonen, 1990), and CCA (Curvilinear Component Analysis) (Demartines \& Herault, 1997). Only the best results are presented (in terms of the projection), which were obtained after tuning the models.

Several experiments were required to tune the SOM (SOM Toolbox for Matlab, 2009) to different options and parameters: grid size, batch/online training, initialization, number of iterations and distance criterion, among others. These parameters were tuned by following the strategies defined in previous SOM models (Kohonen, 1997; SOM Toolbox for Matlab, 2009). In the case of CCA, other parameters, such as initialization, epochs and distance criterion were tuned by following the criteria described in (Demartines \& Herault, 1997).

The study is structured as follows: Section 2 reviews previous work in the field of country and political risk analysis, while Section 3 outlines the application of dimensionality reduction techniques for data analysis and describes the main neural projection models applied in this work. Section 4 describes the first of two case studies in this paper: the Spanish MNEs case study. This section also contains the experimental results obtained by applying the projection models, which are described in Section 3 to 
this dataset. The second case study (Risk Briefing) is presented in Section 5. Section 6 summarizes the conclusions and the future lines of research.

\section{Previous work}

Numerous works have sought to clarify the factors that are involved in decisions concerning the location of foreign investments, whether between developed countries, from developed countries to developing countries or, to a lesser extent, vice-versa from developing to developed countries.

Galan et al. (2007) contains an interesting table with a profuse bibliography of empirical studies that analyze the importance of certain investment-attraction factors. However, it may be said that the analysis of political risk as a fundamental factor in the location of direct investment has received far less attention than other factors, with the notable exceptions of Marois $(1979,1981)$ for French MNEs, (Rich \& Mahmoud, 1990) for Canadian MNEs, (Mortanges \& Allers, 1996) for Dutch MNEs, (Mutinelli \& Piscitello, 1997) for Italian ones and (Noordin, Harjito, \& Hazir, 2006), the last-named work being one of the few to center on multinational enterprises in a less-developed countries; in this case Malaysia. Nevertheless, in certain cases some surveys report that as many as $100 \%$ of enterprises assessed the political risk to which their subsidiaries were exposed (Hashmi \& Guvenli, 1992).

In addition to other intra-firm operational strategies, such as raising the increase of within-firm sales (Feinberg \& Gupta, 2009), the literature has traditionally associated a positive relation between Foreign Direct Investment (FDI) and political risk indices, on which higher scores indicate lower political risk levels. For instance, greater political restrictions imposed by the government add to the credibility of its commitments, which favors investments by foreign MNEs (Henisz \& Zelner, 2001), whilst demands by stakeholder and pressure groups that run contrary to the interests of MNEs are given less attention (Henisz \& Zelner, 2002). Also, greater assurances to ensure compliance with contracts, respect for property rights and greater economic freedom may attract more foreign investments (Bengoa \& Sanchez-Robles, 2003; KapuriaForeman, 2007). Lastly, a lower corruption index score in the host country would have a positive relation with investment inflows, as perceived corruption levels would be lower (Cuervo-Cazurra, 2006, 2008; Wei, 1997).

Nevertheless, results published in Jiménez, Durán, y De la Fuente (2011), García-Canal and Guillén (2008) show that, on some occasions, Spanish MNEs display a preferential bias towards countries with high corruption levels or towards those whose governments may exercise discretionality which would allow them to obtain competitive advantages over their competitors thanks to their negotiating skills gained from their experience of negotiating with governments in their country of origin, or the ease with which they might be able to benefit from corrupt systems. This has also been observed in American MNEs in the electrical sector (Holburn, 2001) that attempt to obtain competitive advantages by investing in countries where their political capabilities may be used to good effect (Henisz, 2003; Hillman \& Hitt, 1999). This is also acknowledged by Brouthers, Gao, and McNicol (2008) who point out that some advantages may be gained in highly corrupt environments through corruption, as it may create resource-allocation efficiencies in countries with underdeveloped economic and legal regulations.

These political capabilities are derived from the Resource-Based View of the firm (Wernerfelt, 1984) and relate to differences between the ability of firms to implement given strategies, depending on their tacit knowledge and skills. These differences tend to be developed in "factor-driven economies", which is to say, in emerging economies where institutional development is more limited and transaction costs are still high due to fragile political stability and bureaucratic inefficiency (Wan, 2005). Thus, MNEs cultivate close relationships with local government to access the resources that such bodies control and allocate.

Whereas the research work cited above tends to rely on variables elaborated by other scholars, MNEs assessing country and political risk traditionally use indices elaborated by private companies (Shell), consulting groups (Business International, Business Environment Risk Index, Political Risk Index or Frost and Sullivan Political Country Reports), specialized journals (The Economist, Institutional Investors or Euromoney) or rating agencies (Moody's, Standard \& Poors or SAP). In our study we offer two case studies, the first one uses three political risk variables frequently used in academic research (Index of Economic Freedom, Corruption Perceptions Index and Political Constraint Index) while the second case is based on data from one of the most important consulting groups (the Risk Briefing dataset from the Economist Intelligence Unit), thereby providing a comprehensive view of data from both academia and private companies.

Very few works have focused the identification of country and/ or political risk from an Artificial Intelligence perspective. Juliana and Heather (2005) propose hierarchical clustering and ANN to predict country and sovereign risk rating within a macroeconomic context, approaching this task from a classification standpoint. On the contrary, and within a more microeconomic and "businessstrategy" context, the present paper addresses the influence and role of political risk in the international expansion of Spanish MNEs from a visualization (through dimensionality reduction) standpoint.

\section{Dimensionality reduction visualization for data analysis}

Projection methods project high-dimensional data points onto lower dimensions in order to identify "interesting" directions in terms of any specific index or projection. Such indices or projections are, for example, based on the identification of directions that account for the largest variance of a dataset (such as Principal Component Analysis (PCA) (Hotelling, 1933; Oja, 1989; Pearson, 1901 ) or the identification of higher-order statistics such as the skew or kurtosis index, which is the case of EPP (Friedman \& Tukey, 1974). Having identified the interesting projections, the data is then projected onto a lower dimensional subspace plotted in two or three dimensions, which makes it possible to examine its structure with the naked eye. The remaining dimensions are discarded as they mainly relate to a very small percentage of the information or the dataset structure. In that way, the structure identified through a multivariable dataset may be visually analyzed with greater ease.

The combination of this type of technique together with the use of scatter plot matrixes constitutes a very useful visualization tool to investigate the intrinsic structure of multidimensional datasets, allowing experts to study the relations between different components, factors or projections, depending on the technique that is used.

\subsection{Cooperative Maximum-Likelihood Hebbian Learning}

The standard statistical EPP method (Friedman \& Tukey, 1974) provides a linear projection of a dataset, but it projects the data onto a set of basic vectors which best reveal the interesting structure in data; 'interestingness' is usually defined in terms of how far the distribution is from the Gaussian distribution.

One neural implementation of EPP is Maximum-Likelihood Hebbian Learning (MLHL) (Corchado, MacDonald, \& Fyfe, 2004; 
Fyfe \& Corchado, 2002), which identifies interestingness by maximizing the probability of the residuals under specific probability density functions that are non-Gaussian.

An extended version of this model is the Cooperative Maximum-Likelihood Hebbian Learning (CMLHL) (Corchado \& Fyfe, 2003) model. CMLHL, which is based on MLHL (Corchado et al., 2004; Fyfe \& Corchado, 2002) adds lateral connections (Corchado \& Fyfe, 2003; Corchado, Han, \& Fyfe, 2003) which have been derived from the Rectified Gaussian Distribution (Seung, Socci, \& Lee, 1998). The resultant net can find the independent factors of a data set but does so in a way that captures some type of global ordering in the data set.

Considering an $\mathrm{N}$-dimensional input vector $(x)$, and an $M$ dimensional output vector $(y)$, with $W_{i j}$ being the weight (linking input $j$ to output $i$ ), then CMLHL can be expressed (Corchado \& Fyfe, 2003; Corchado et al., 2003) as:

1. Feed-forward step:

$$
y_{i}=\sum_{j=1}^{\mathbf{N}} W_{i j} x_{j}, \quad \forall i .
$$

2. Lateral activation passing:

$$
y_{i}(t+1)=\left[y_{i}(t)+\tau(b-A y)\right]^{+} .
$$

3. Feedback step:

$$
e_{j}=x_{j}-\sum_{i=1}^{M} W_{i j} y_{i}, \quad \forall j .
$$

4. Weight change:

$$
\Delta W_{i j}=\eta \cdot y_{i} \cdot \operatorname{sign}\left(e_{j}\right)\left|e_{j}\right|^{p} .
$$

where $\tau$ is the "strength" of the lateral connections between the output neurons, $b$ the bias parameter, $A$ a symmetric matrix used to modify the response to the data (Corchado \& Fyfe, 2003), $\eta$ is the learning rate and $p$ a parameter related to the energy function (Corchado \& Fyfe, 2003; Corchado et al., 2004; Fyfe \& Corchado, 2002). The effect of the $A$ matrix is based on the relation between the distances separating the output neurons.

CMLHL has been previously applied as a dimensionality reduction technique in some other fields such as Computer Network Security (Corchado \& Herrero, 2011; Herrero et al., 2009) or Knowledge Management (Herrero et al., 2010).

\subsubsection{Fine tuning}

The CMLHL fine-tuning process is based on the effect of changing the $\tau$ parameter. Experiments (Corchado \& Fyfe, 2003) using the bars data set (Földiák, 1992), which add noise in a graduated manner across the outputs, have conclusively proven that the strength of the $\tau$ parameter directly affects the ability of the neural network to "gather" features together on the outputs. A low $\tau$ value allows the neural model to code both horizontal and vertical bars around a mode. If there is an increase in the $\tau$ value, the weak correlations between horizontal and vertical bars begin to have an impact on the learning. As the lateral connections become stronger, the bars are still learning one particular mode, but at the same time different orientations start to branch off. Finally, a separation between the two different orientations emerges, which is an interesting development as all the data presentations to the network consist of both horizontal and vertical bars.
Further increases in the $\tau$ value force the network to learn only one orientation of bars. However, if the lateral connections are too strong, then the coding of the bars may be squashed into an area of the output space that is too small for all of the bars to be coded individually. The reason why one orientation of bars is suppressed is due to the pixel overlap between different orientations of bars. If the lateral excitation between the output neurons is strong enough, a single output neuron may be able to switch its preference from a horizontal to a vertical bar.

Corchado and Fyfe (2003) consider that such switches in orientation identification were precursors to the creation of horizontal/ vertical conceptualization in animals inhabiting a mixed environment.

\subsection{Self-Organizing Map}

The Self-Organizing Map (SOM) (Kohonen, 1990) was developed as a visualization tool for representing high dimensional data on a low dimensional display. It is also based on the use of unsupervised learning. However, it is a topology preserving mapping model rather than a projection architecture.

The cerebral cortex of the human brain is one of the most complex biological systems. The different areas defined in this region are organized according to various sensory modalities: speech control, visual analysis, auditory control, etc. Each one of these areas consists of a large number of similar neurons that cooperate when carrying out their specific functions in which they have become specialized: auditory or hearing receptors, visualization, etc. Groups of neurons within each region respond jointly to excitations from the sensory cell they service (Patterson, 1998). There is a mapping of the features from sensory neurons to the associated spatial regions of the cortex. This biological feature mapping of the brain has been modeled reasonably well with ANNs. The computed SOMs are very similar to many brain maps as they also behave dynamically, in the same way, for example, as their magnification is adjusted in proportion to the occurrences of the stimuli (Kohonen, 1997). Thus the SOM (Baruque $\&$ Corchado, 2010) is a proper example of artificial topology preserving maps, where closer neurons are activated by similar inputs or stimuli.

To mimic the biological brain maps, the SOM is composed of a discrete array of $L$ nodes arranged on an $N$-dimensional lattice. These nodes are mapped into a $D$-dimensional data space while preserving their ordering. The dimensionality of the lattice $(N)$ is normally smaller than that of the data, in order to perform the dimensionality reduction. The SOM can be viewed as a non-linear extension of PCA, where the global map manifold is a non-linear representation of the training data (Ritter, Martinetz, \& Schulten, 1992).

Typically, the array of nodes is one or two-dimensional, with all nodes connected to the $N$ inputs by an $N$-dimensional weight vector. The self-organization process is commonly implemented as an iterative on-line algorithm, although a batch version also exists. An input vector is presented to the network and a winning node, whose weight vector $W_{c}$ is the closest (in terms of Euclidean distance) to the input, is chosen:

$c=\arg \min _{i}\left(\left\|\mathbf{x}-W_{i}\right\|\right)$.

The SOM is therefore a vector quantizer, and data vectors are quantised to the reference vector in the map that is closest to the input vector. The weights of the winning node and the nodes close to it are then updated to move closer to the input vector. There is also a learning rate parameter $(\eta)$ that usually decreases as the training process progresses. The weight update rule is defined as:

$\Delta W_{i}=\eta h_{c i}\left[\mathbf{x}-W_{i}\right], \quad \forall i \in N^{(c)}$. 
When this algorithm is sufficiently iterated, the map self-organises to produce a topology-preserving mapping of the lattice of weight vectors to the input space based on the statistics of the training data.

This neural model is applied here for comparative purposes as it is one of the most widely used unsupervised neural models for visualizing structure in high-dimensional data sets.

\subsection{Curvilinear component analysis}

Curvilinear Component Analysis (CCA) (Demartines \& Herault, 1997 ) is a nonlinear dimensionality reduction method. Developed as an improvement on the SOM, it tries to circumvent the limitations inherent in previous linear models such as PCA.

The principle of CCA is a self-organized neural network performing two tasks: a vector quantization of the submanifold in the data set (input space) and a nonlinear projection of these quantising vectors toward an output space, providing a revealing view of the way in which the submanifold unfolds. Quantization and nonlinear mapping are separately performed by two layers of connections: firstly, the input vectors are forced to become prototypes of the distribution using a vector quantization (VQ) method; then, the output layer builds a nonlinear mapping of the input vectors by considering Euclidean distances.

In the vector quantization step, the input vectors $\left(x_{i}\right)$ are forced to become prototypes of the distribution by using competitive learning and the regularization method (Demartines, 1994) of vector quantization. Thus, this step, which is intended to reveal the submanifold of the distribution, regularly quantizes the space covered by the data, regardless of the density. Euclidean distances between these input vectors $\left(X_{i j}=d\left(x_{i}, x_{j}\right)\right)$ are considered, as the output layer has to build a nonlinear mapping of the input vectors. The corresponding distances in the output space are also used $\left(Y_{i j}=d\left(y_{i}, y_{j}\right)\right)$.

Perfect matching is not possible at all scales when the manifold is "unfolding", so a weighting function $\left(F\left(Y_{i j}, \lambda_{y}\right)\right)$ is introduced, yielding the quadratic cost function:

$E=\frac{1}{2} \sum_{i} \sum_{j \neq i}\left(X_{i j}-Y_{i j}\right)^{2} F\left(Y_{i j}, \lambda_{y}\right)$,

where $\lambda$ is a user-tuned parameter allowing an interactive selection of the scale at which the unfolding takes place.

As regards its goal, the projection part of CCA is similar to other nonlinear mapping methods, in that it minimizes a cost function based on interpoint distances in both input and output spaces. Instead of moving one of the output vectors $\left(y_{i}\right)$ according to the sum of the influences of every other $y_{j}$ (as would be the case for a stochastic gradient descent), CCA proposes pinning down one of the output vectors $\left(y_{i}\right)$ "temporarily", and moving all the other $y_{j}$ around, disregarding any interactions between them. Accordingly, the proposed "learning" rule can be expressed as:

$\Delta y_{j}=\alpha(t) F\left(Y_{i j}, \lambda_{y}\right)\left(X_{i j}-Y_{i j}\right) \frac{y_{j}-y_{i}}{Y_{i j}}, \quad \forall j \neq i$,

where $\alpha()$ is the step size that decreases over time.

\section{The Spanish MNEs case study}

The sample of enterprises on which the present study is based is made up of Spanish multinational enterprises of over 250 employees, which in December 2007 appeared on the list of the Spanish Institute of Foreign Commerce (ICEX - Instituto de Comercio Exterior), the web page of the Spanish Ministry of Industry, Tourism and Commerce (Network of Economic and Commercial Spanish Offices Abroad, 2009), and other foreign bodies concerned with foreign direct investment, which may be contacted through the ICEX, that compile directories of Spanish MNEs with investments in their countries.

\subsection{The dataset}

In total, the sample is formed of 166 Spanish MNEs, which have 1812 subsidiaries localized across the world, for which the data on the necessary variables was obtained for 1152 subsidiaries. Thus, the dataset is composed of 1152 observations relating to 12 variables, namely: Index of Economic Freedom, Corruption Perceptions Index, Political Constraints Index (POLCONV), total assets, employee numbers, Return on Equity (ROE), growth rate of sales, solvency ratio, number of foreign countries in which the MNE has its subsidiaries, Foreign Direct Investment/Gross Domestic Product (FDI/GDP), GDP growth, and total population.

The first of these variables, was the mean average that the Index of Economic Freedom devised by the Heritage Foundation (Index of Economic Freedom, 2005) assigned to each country for the years 2004 and 2005. This index is made up of various variables that measure the independence of the judicial system, the ability of firms and individuals to ensure full compliance with contracts, corruption within the judicial system, the degree to which the government protects the property rights and the degree of freedom that exists for businesses, commerce and investment. The mean average of the 2004 and 2005 Corruption Perceptions Index devised by Transparency International (Corruption Perceptions Index, 2008) has been already included in the dataset. This index is used to measure corruption as perceived by business leaders and experts from each country. As complementary data, the dataset also includes the mean average of the last five years of Henisz's Political Constraint Index (POLCONV) (Henisz, 1998). In this index, the number of independent authorities with a power of veto is taken into account, the score being modified in accordance with the possible alignments between authorities, such that they affect the actual constraints to which the government is subjected. Additional modifications are also made when some political authorities are neither totally aligned nor totally opposed, to take account of their composition when determining the degree of political constraint. By using several measures, we take into account different aspects of political risk, giving a better picture of the host country's overall governance infrastructure (Slangen \& van Tulder, 2009).

Additionally, the dataset includes several firm characteristics such as: total assets, employee number, Return on Equity (ROE), growth rate of sales, solvency ratio and the number of foreign countries in which the MNE has its subsidiaries. Some country macroeconomic characteristics are also included: Foreign Direct Investment/Gross Domestic Product (FDI/GDP) as a measure of the openness of the destination economy, GDP growth as a measure of the attractiveness of the country and total population as a measure of the size.

The previously introduced dimensionality reduction techniques (see Section 3) were applied to the Spanish MNEs dataset. The projections obtained by these neural projection models are set out and analyzed in the following sections.

\subsection{PCA projection}

PCA was applied to the Spanish MNEs dataset. Fig. 1 presents the PCA projection onto the two first principal components.

\subsection{CMLHL projection}

The following CMLHL projections (Figs. 2-4) reflect the different motivations driving Spanish MNEs to localize in countries 


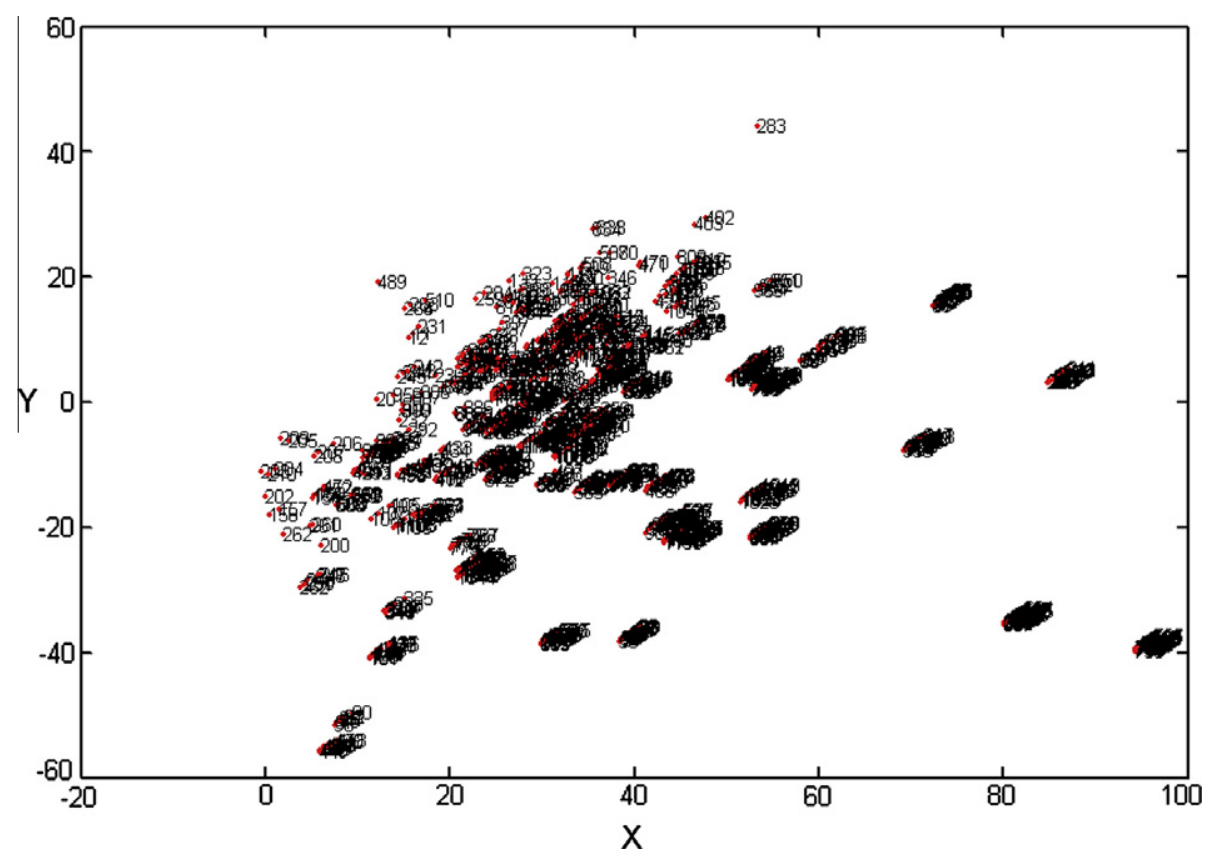

Fig. 1. PCA projection of the Spanish MNEs dataset.
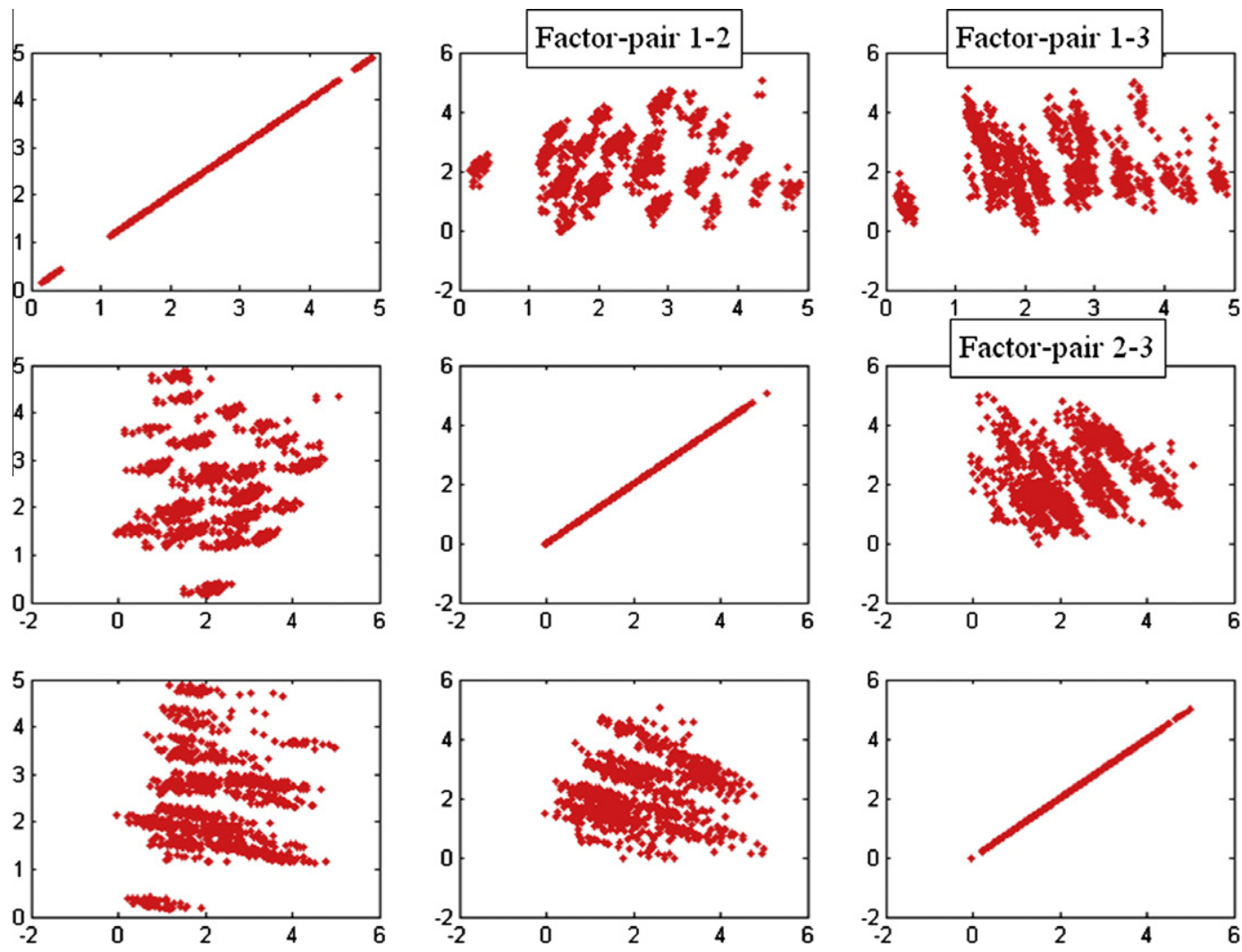

Fig. 2. CMLHL scatter plot matrix for the Spanish MNEs dataset.

within the different regions under analysis, which represent, to a great degree, the main host countries traditionally targeted by Spanish foreign direct investment. These projections were obtained by applying the following values to the different CMLHL parameters: number of iterations $=4.000$, learning rate $=0.0208$, $p$ parameter $=1.2$, and $\tau$ parameter $=0.11$.

Fig. 2 depicts all the possible combinations of the third first factor pairs obtained through CMLHL by means of a scatter plot matrix. Factor pairs under the diagonal provide no extra information.

The main results obtained by CMLHL (factor pairs 1-2 and 1-3 from Fig. 2) are analyzed in depth in this section.

\subsubsection{CMLHL factor pair 1-2}

The groups identified in the CMLHL factor pair 1-2 analysis (Fig. 3) are described as follows. 


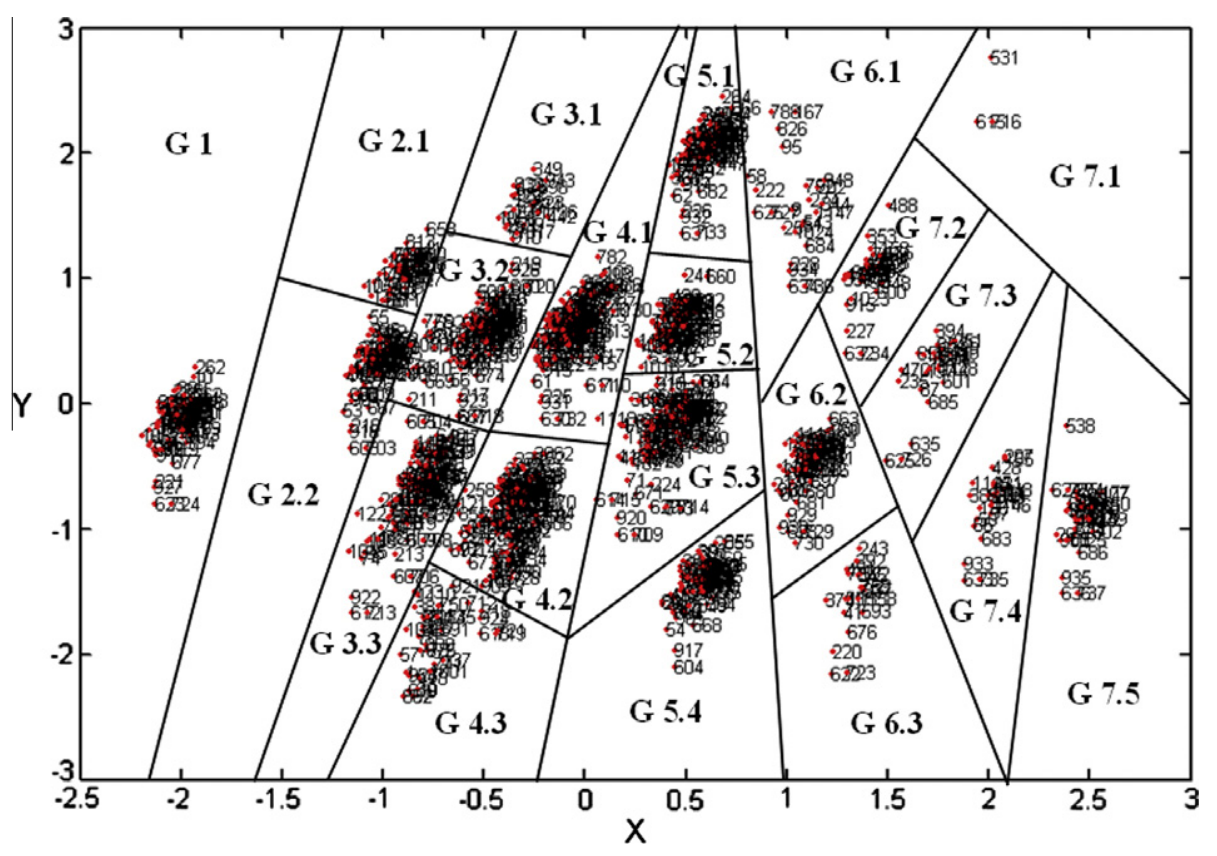

Fig. 3. CMLHL factor pair 1-2 for the Spanish MNEs dataset.

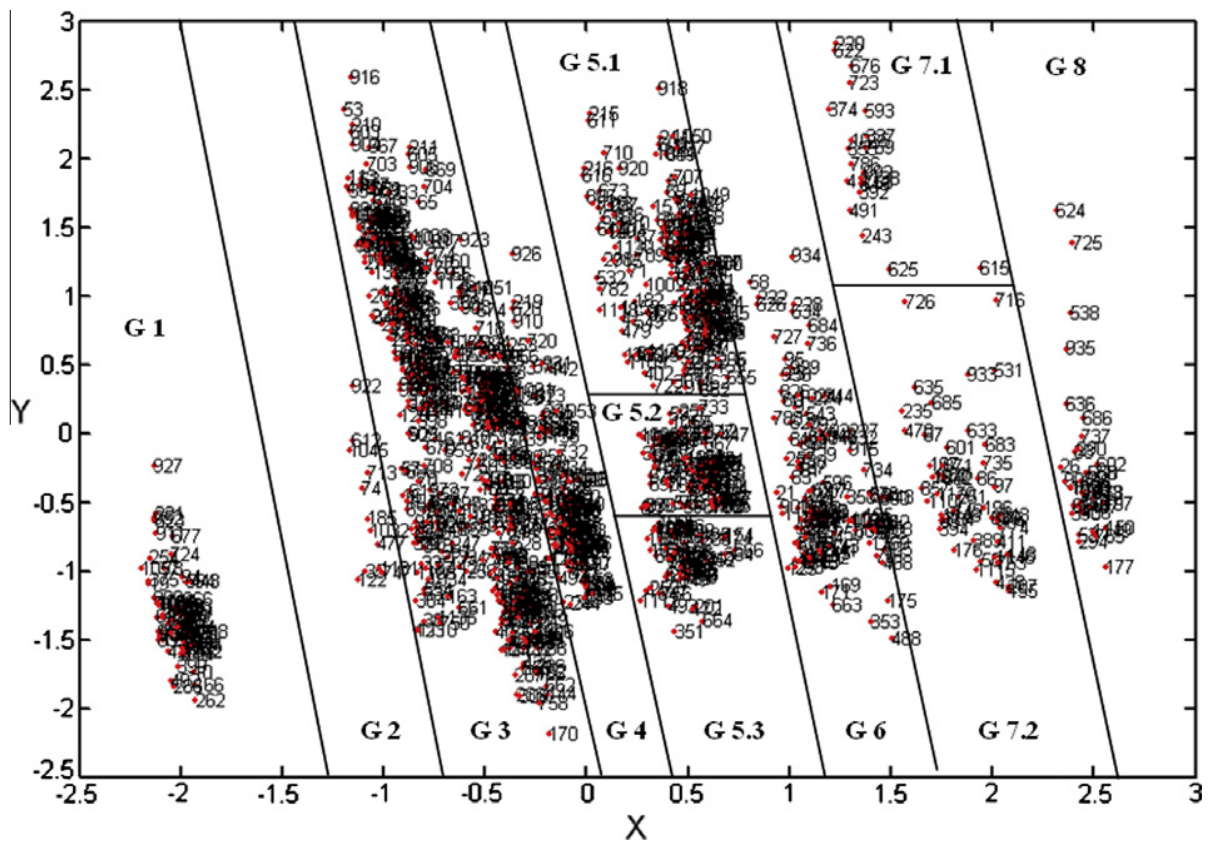

Fig. 4. CMLHL factor pair 1-3 for the Spanish MNEs dataset.

4.3.1.1. Group 1 (64 records). On the whole, this group is characterized by subsidiaries with a presence in European countries such as France, Ireland, Netherlands and Hungary. Subsidiaries may also be found in Latin-American countries - Brazil, Honduras, Colombia and Venezuela - though it is an almost token presence. In addition, the average size of these enterprises is smaller than the rest of the sample, and they have a varied sectoral composition. Thus, given the limited amount of available resources to launch their internationalization strategies, the enterprises in this group have sought to capitalize on the competitive advantages of the sectors to which they belong, acquired from their experience in the domestic market. Accordingly, they select specific markets and attempt to assure a solid competitive position.
4.3.1.2. Group 2.1 (35 records). The most relevant European countries in this group are Germany and Austria, with a slight presence in Portugal of scant importance. Latin America is almost entirely represented by Argentina and Venezuela. In this case, the composition is less varied than in the preceding case, as these are subsidiary enterprises in the services sector, and here too the sizes of their parent enterprises are below average. It is noteworthy that the lowest scores on the Index of Economic Freedom for the sample are attributed to these countries, as once again they reveal a group that bases its internationalization strategy on competitive advantages, with little regard for the level of security offered by a high score on the Index of Economic Freedom, consistent with the results published in Jiménez et al. (2011), García-Canal and Guillén (2008). 
4.3.1.3. Group 2.2 (63 records). Once again, Venezuela is the country to which the major part of direct Spanish investment is directed in this region, and other locations appear alongside it in the Dominican Republic, Peru and Uruguay. For its part, Europe is fundamentally represented by the UK, Czech Republic, Sweden and only slightly so by Portugal. This group has similar characteristics to group 2.1, as it is principally made up of smaller-sized enterprises in the services sector. The main difference lies in the location from which the enterprises can exploit their competitive advantages, which in this case tends to be in countries whose legal systems are based more on common law, as opposed to the preceding group, whose codified legal systems are influenced more by Roman law (civil law).

4.3.1.4. Group 3.1 (19 records). This is a group with few members, in which only France, Greece and Guatemala are present. Enterprises of all sizes may be found, although predominantly from the manufacturing sector. They are not especially concerned by the degree to which ownership rights are protected or whether compliance with contracts are guaranteed; a fact that is reflected by somewhat lower scores on the Index of Economic Freedom, showing a proactive use of political risk in the host countries.

4.3.1.5. Group 3.2 (97 records). In this case, the most widely represented European countries are Germany, Belgium, Slovakia, Slovenia and Finland. Relatively well distributed, they have a similar presence in all Latin America locations spread across Argentina, Brazil, Chile, Colombia and El Salvador. In this case, the enterprises are of a larger-than-average size, and manufacturing enterprises predominate, as they do in the latter subgroup, although financial and banking enterprises are also found. These are enterprises which, given their greater volume of resources, launch their internationalization strategies in Germany and in the largest LatinAmerican countries, although they will also set up wherever they find an attractive growing market. It is the case at present of some countries that have recently joined the European Union.

4.3.1.6. Group 3.3 (98 records). This subgroup, as is largely the case throughout Group 3, is made up of large enterprises, able to launch their internationalization strategy in the major economies of each region, but also wherever they come across a business opportunity. In this case, however, the locations are centered principally on Chile, although Argentina, Bolivia and Ecuador also stand out; and Belgium, within Europe, along with Germany and Austria, although it is one of the subgroups in which the European presence is the least significant.

4.3.1.7. Group 4.1 (121 records). The presence in this subgroup of Poland and Estonia is very relevant, as they are the largest economies among all of the countries that joined the European Union in its expansion eastwards. With respect to the former, the great majority of Spanish subsidiary locations are found in this group, but with respect to the latter, all (although it should be said that there are not very many) the locations are found within this subgroup. Mexico, Panama and Costa Rica may be highlighted in Latin America, but behind the main destination that is Peru. The size of the enterprises is in line with sample average, with a slight bias in favor of the larger enterprises. As regards their sectors, service enterprises are the most abundant in absolute terms, but mining and construction enterprises are the protagonists if the data are analyzed in relative terms.

4.3.1.8. Group 4.2 (117 records). Within Europe, France, Italy, and Luxembourg all stand out, as well as, to a lesser extent, the Netherlands, Ireland and Denmark, whereas in Latin America, the presence of subsidiaries is evenly distributed between Argentina,
Brazil, Chile, and Colombia. Costa Rica and Panama may be highlighted as countries which, despite being less attractive traditional destinations for Spanish investment because of the smaller size of their economies, have a similar number of subsidiaries as the other countries in this group. Average size is again slightly biased towards the larger enterprises, although the importance of this slight bias is minimized, if we bear in mind that these subgroups have the highest number of enterprises. Once again, the role played by enterprises in the mining and construction sectors is relevant, although in this case they are accompanied by enterprises from the financial sector. It is worth recalling the significant investments made by the large Spanish banks in the principal countries of Latin America and in Central Europe, which are precisely the locations that are covered in this section.

4.3.1.8.1. Group 4.3 (35 records). This Group is the smallest within Group 4, in which the European presence in Belgium, France and Greece predominates, whereas on the Latin American side there are locations in Argentina, Costa Rica, El Salvador and Venezuela, although of slight importance. There is an even distribution between large and small multinational enterprises, but it is very biased towards the services sector, which is a differentiating feature of this subgroup with respect to the preceding ones.

4.3.1.9. Group 5.1 (68 records). Unquestionably, the determining feature of this subgroup is the presence of subsidiaries in Portugal - 52 of the 68 records -, together with a slight presence in Poland. The only Latin American locations are found in a further group that is characterized by its presence in Europe, Mexico and Peru. Undoubtedly, this subgroup is made up of enterprises that are searching for a location in countries with close cultural similarities, which is why they choose southern Europe and Latin America, while remaining attentive to the political constraints faced by the government, in an attempt to minimize the negative impact that unilateral decisions taken by the host government could have on the interests of the subsidiary enterprise, in line with the results obtained by Henisz and Zelner $(2001,2002)$. The fact that average enterprise sizes are smaller reinforces this hypothesis, as enterprises with fewer resources have to be more cautious when selecting their locations and to try to avoid mandatory contractual modifications or even nationalizations or expropriations in the worst case scenario; regardless of the individual economic sectors in which they are based, their presence is evenly distributed across them all.

4.3.1.10. Group 5.2 (62 records). The presence in Europe is quite evenly distributed, with Belgium, France and Holland at the top of the list. However, the Latin American side is fundamentally composed of the large-scale economies of Argentina and, above all, Brazil. It is a widely distributed group with regard to its composition both by size and by sector, and is characterized by the "conservative" nature of its locations; a concept understood in terms of investments in neighboring countries in the case of Europe, and in the larger economies with sizeable markets and a potentially broader consumer base, where they take an initiative to invest in a more distant location such as Latin America. In all cases, the most secure countries are chosen in view of corruption levels, economic freedoms, political restrictions and the cultural distance of these countries with respect to the other investment alternatives in each region, showing additional evidence of the relation found by Bengoa and Sanchez-Robles (2003), Cuervo-Cazurra (2006, 2008), Kapuria-Foreman (2007), Wei (1997).

4.3.1.11. Group 5.3 (103 records). This is the most numerous subgroup within Group 5, in which both France and Italy stand out on the European side, and mainly Mexico and Peru, but also Brazil, Chile, Colombia, and El Salvador, in a subgroup in which the 
presence, to a greater or lesser extent, of practically all the Latin American countries may be underlined. Once again the composition of the sample is well distributed by size and by economic sector. The internationalization strategy followed in this subgroup is similar to the preceding group, in that the enterprises select countries within Europe that are very near to Spain, although it is more diversified with regard to the location choices in Latin America.

4.3.1.12. Group 5.4 (59 records). Once again, this is a subgroup where the European presence outweighs the Latin American presence; 47 of the 59 records belong to subsidiaries localized in the 'old continent'. The two countries with the greatest presence in this group are principally Germany, followed by Portugal. On the Latin American side, the presence in the majority of countries may be described as almost solely symbolic, except for the presence in Venezuela. Once again, this is a conservative strategy, as the two destinations appear that were missing among those countries that were fundamentally targeted by direct foreign investment from Spain. As in Group 5, enterprises from all sectors may be found, but they are characterized by a very small below-average size, which explains this tendency to prioritize investment security in predictable well-known institutional settings that are close to home.

4.3.1.13. Group 6.1 (24 records). This is a small subgroup in which the UK, Czech Republic, Italy and Lithuania stand out on the European side, whereas on the Latin American side, practically all of the locations are in the Dominican Republic. Their sizes are somewhat above average. Following an analysis of the sectoral composition, it is worth stressing the prominence of fashion wholesalers and retailers; principally the multinationals with an interest in fashion. The strategy of this subgroup is not entirely defined. This is easily identifiable in the graph of the factor pair 1-2 projection, where it can be appreciated how its constituent elements are relatively spaced out in comparison with the distance between the elements of the other subgroups.

4.3.1.14. Group 6.2 (57 records). This group is almost exclusively made up of locations in Latin America - 54 of a total of 57 records - which is why Mexico, Nicaragua, Panama and Paraguay, though no single European country may be highlighted. The enterprises in this subgroup are of a considerable size and are active in the mining, construction and services sectors. The principal Spanish multinationals (Telefónica, Repsol, ACS, Inditex, BBVA, BSCH) all have at least one subsidiary in this group that is characterized by very low corruption and political constraint indices. It is therefore evident that these locations respond to an internalization strategy that is guided by exploiting skilled negotiations with local authorities or indeed by benefiting from facilities offered to Spanish MNEs by the more corrupt systems that hold sway in these countries to consolidate positions with competitive advantages, at least in the short term, in line with the results in (Jiménez et al. (2011), García-Canal and Guillén (2008), Holburn (2001). However, in the long term, this can lead to problems relating to obligatory contractual modifications or expropriations (Jiménez et al., 2011; GarcíaCanal \& Guillén, 2008).

4.3.1.15. Group 6.3 (19 records). This is another sparsely populated group, in which Hungary, Greece and Guatemala figure prominently, with enterprises of an intermediary size that are in the wholesale and retail sectors, as in group 6.1. They have no clear internationalization strategy, which is evident from the high degree of dispersion between their constituent elements; they differ exclusively in those countries selected as investment destinations.
4.3.1.16. Group 7.1 (3 records). This is a mini-group formed by three subsidiaries in small Eastern European countries such as Slovakia and Slovenia. All three belong to large Spanish MNEs (Iberdrola, Inditex and Mango) but they can almost be considered as special cases in the analysis.

4.3.1.17. Group 7.2 (28 records). The principal destination of this subgroup is the UK, with 19 of the 28 records, while Portugal has much fewer. Only three records are found in Latin America and no one country may be highlighted. The average size is evenly distributed, but a high presence may be appreciated in the manufacturing sector, which seeks countries in this subgroup with high scores for the indices of corruption, political constraints and economic freedom. It differs from the preceding groups where this sector was prominent, but where the internationalization strategy paid less attention to political risk associated with investments.

4.3.1.18. Group 7.3 (24 records). In this group, the subsidiaries are localized in Latvia, Portugal, Czech Republic and Sweden, along with the Dominican Republic solely on the Latin American side. They are large enterprises, with the presence of various wellknown multinationals (Telefónica, Inditex, BBVA, BSCH), which take advantage of their greater volume of resources as was the case of groups 3.2 and 3.3, (it may be seen that they are found at a similar height in factor pair 1-2 projection - Fig. 3), to expand not only in the reference markets of each zone, but in other less accessible markets that nevertheless offer good business opportunities.

4.3.1.19. Group 7.4 (22 records). This group is characterized by the massive presence of subsidiaries in the UK, which contrasts with the absence of locations in Latin America. This phenomenon is easily explainable if the large size of the subsidiaries and above all their sector is taken into account. Thus, there is predominance of financial entities in London, the financial heartland of the 'Old Continent', where they have set up operational bases for their international clients.

4.3.1.20. Group 7.5 (35 records). Finally, in this last group, locations of large multinationals across all sectors are found in Sweden, the UK and Uruguay, which seek countries where all the indices relating to economic freedoms and to protection of ownership rights are very high.

4.3.1.21. General conclusions. The projection model employed in this study (CMLHL) has enabled us to distinguish different motivations that drive enterprises to localize in the regions under study, the vast majority of which represent the main destinations traditionally targeted by Spanish foreign investment.

Thus, it has been observed how Group 1 is characterized by smaller enterprises that could not allow their resources to be misspent on risky internationalization strategies. Something similar took place in Group 2, in which small service sector enterprises are concentrated, and in which it is possible to distinguish two sub-groups according to the countries which manage them.

Group 3 however, contains enterprises with very different characteristics, in which the manufacturing sector may be highlighted and large enterprises with complex internationalization strategies on account of the level of resources they can invest.

For its part, Group 4, which contained the highest number of enterprises in the entire sample, showed the groupings of enterprises working in construction that is currently quite a controversial sector, which have targeted both developed economies with large markets and recent members of the European Union that have better forecasts for growth and profitability. Nonetheless, the existence of subgroups where the presence of Eastern European countries is so predominant, as in Group 4.1, demonstrates 
that these countries, despite having made significant economic and social progress, still constitute an investment destination, with specific characteristics which differ from the other European partners in the European project; findings that are in agreement with those of Durán, De la Fuente, and Jiménez (2008).

Group 5, with all of its subgroups, has shown how some MNEs seek to minimize the risk associated with foreign investment by investing in countries that are culturally akin to their own, searching for better management and solutions to the problems that may arise. This group is the best example of the negative relation between political risk and FDI demonstrated by Bengoa and Sanchez-Robles (2003), Cuervo-Cazurra (2006, 2008), Kapuria-Foreman (2007), Wei (1997).

Group 6 is particularly interesting as it is made up of the flagships of Spanish foreign investment. Moreover, they demonstrate a degree of short-termism in their investment strategy in Latin America, seeking to gain an attractive competitive position at the start of the investment period, but unconcerned about the problems that are inherent to political risk. This proactive use of political risk is consistent with the results obtained by Jiménez et al. (2011), García-Canal and Guillén (2008), Holburn (2001).

Finally, Group 7 constitutes a set of locations where most subgroups have been identified, and in which the high dispersion of their constituent elements may easily be appreciated. It is here that those enterprises with less obvious internationalization strategies are found, on occasions similar to those of other groups, but in different countries or with enterprises from varied sectors.

\subsubsection{CMLHL factor pair $1-3$}

As a complementary projection to the factor pair 1-2 analysis (Fig. 3), Fig. 4 shows the CMLHL factor pair 1-3. The different groups identified in this figure are analyzed in the following paragraphs.

4.3.2.1. Group 1 (64 records). This is a group made up of large enterprises, which are diversified but with a slightly higher presence of the manufacturing sector, with subsidiaries in France, the Netherlands, and Hungary, and a scant Latin American presence, which is similar to group 1 in the factor pair 1-2 analysis.

4.3.2.2. Groups 2, 3 and 4 (12, 421 and 122 records). These three groups are found very close to each other as may be seen in Fig. 4 showing the distribution of the factor pair 1-3 analysis, on which basis some shared approaches to the internationalization strategy conducted by these multinationals may be defined. Also, the large enterprises predominate in this case, with a presence across all sectors, and in a variety of both European and Latin American countries, due to the high number of individuals that make up this group. If subgroups were defined, as was done with the factor pair 1-2 analysis, closer sets would be observed in different zones in the upper, medium and lower part of the graph, but generally speaking these groups coincide with groups 2,3 and 4 (composed by their respective subgroups) identified by the factor pair 1-2 analysis.

4.3.2.3. Group $5(169+86+57$ records). Once again, a group with numerous enterprises of all sizes, from all possible sectors and country locations: as in the previous case, the subgroups in group 5 may be likened in a general way to those in the factor pair 1-2 analysis with regard to sectoral distribution and country location, although with some small differences with regard to size, as the bias towards small enterprises in the preceding analysis is not as clearly defined as in this case.

4.3.2.4. Group 6 (109 records). The UK, the Czech Republic, and Italy are prominent in Europe, and likewise, Mexico, Panama and
Nicaragua in Latin America. Once again, group 6 in this analysis jointly covers subgroups 6.1 and 6.2 in the preceding analysis, although in this case it does not include subgroup 6.3, the relevance of which, it may be recalled, was minor.

4.3.2.5. Group $7(23+45$ records). This is a much less numerous group, in which the Dominican Republic, the UK and Portugal play the most important roles, with some contributions from Sweden, Latvia and Poland, which repeats the pattern analyzed in the 1-2 component, but without including strategies that are to a certain extent more "marginal" such as those of subgroups 7.1 and 7.5.

4.3.2.6. Group 8 ( 34 records). Subgroup 7.5 which was not included beforehand does appear in this additional group that is contributed by the factor pair 1-3 analysis. Uruguay, Sweden and the UK all have a notable presence.

4.3.2.7. General conclusions. In general terms, the factor pair 1-3 analysis adds weight to the conclusions drawn from the factor pair 1-2 analysis, as its groups contain more enterprises that cover the internationalization strategies detected earlier, although in summary form as it identifies far fewer subgroups. The analysis is therefore more general, which prevents the detection of slightly more heterogeneous groups, and less well-defined strategies, as was the case of subgroups 6.3 or 7.1, or certain subtle size-related biases. This analysis divided the former group 7 into two groups 7 and 8 - but it assimilated the former subgroup 7.5 which appears at the extreme edge of the graph of the factor pair 1-2 analysis, which meant that this second analysis considered it to be a different group; although always with an importance well below groups $3,4,5$ and 6 . These constitute the principal groups in which Spanish foreign investment is concentrated, and where the internationalization strategies are found: on some occasions more traditional and conservative, on others more risk oriented or even, as shown by the bias towards countries with high levels of corruption, clearly motivated by short-termism (Jiménez et al., 2011).

\subsection{SOM mapping}

The SOM mapping of the dataset is visualized by means of:

- $U$-matrix (Fig. 5): distance matrix between the reference vectors of adjacent neurons of a two-dimensional lattice.

- Numbered map (Fig. 6): neurons in the rectangular lattice have been labeled with a number. These numbers represent the amount of companies associated with each neuron. To ease the analysis of this result, neurons have been grouped according to their location in the map. Additionally, to make this mapping more intuitive, the neurons have been colored following a topological ordering.

These results are analyzed in the following paragraphs. The parameter values that generated this mapping were: random initialization, batch training, hexagonal lattice, and cut Gaussian neighborhood function. The grid size was determined by means of a heuristic formula.

\subsubsection{Group 1 (47 records)}

This group is made up of larger-than-average size firms from the wholesale and retail commercial sectors as well as from the financial services sector. Firms are concentrated in Belgium, followed by other countries such as Austria, UK and the Netherlands. Their strategies all reflect low levels of political risk and their locations are widely diversified in Latin America, where countries with low and high levels of political risk coexist alongside each other. 


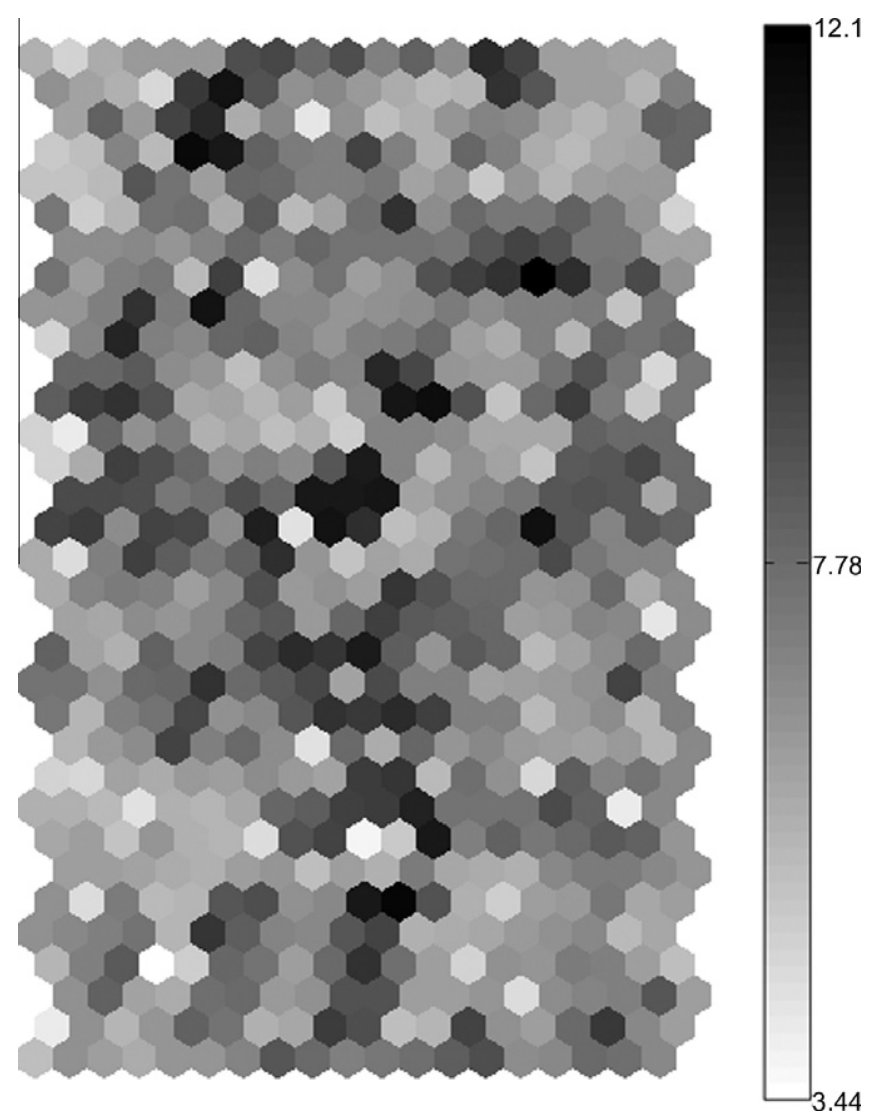

Fig. 5. SOM $U$-matrix of the Spanish MNEs dataset.

\subsubsection{Group 2 (233 records)}

This is the most numerous group in the SOM mapping, with firms of all sizes, although there is a slight predominance of larger-sized firms and the sample is very biased towards service sector firms. Their presence in Europe is widespread in countries that have traditionally been targeted by Spanish investment: France and Portugal, though a presence in Belgium, and Poland and Slovakia may once again be highlighted. Brazil, Chile and Venezuela are the main destinations for investment in Latin America. It is therefore a matter of companies that invest in markets which are geographically and culturally close to Europe and that prioritise other competitive advantages over and above the reduction of the risks that they encounter, as these remain within reasonable limits. Within Latin America, the firms prefer to opt for larger-sized markets with large numbers of potential consumers, higher income levels and lower levels of political risk. This is consistent with the majority of firms being found in the service sector, as their penetration into this region is driven by the search for new markets and not by a desire for cost reductions or greater efficiency.

\subsubsection{Group 3 (5 records)}

This is a group composed of only five firms, which may therefore be considered a special case that does not deserve any attention.

\subsubsection{Group 4 ( 88 records)}

Group 4 is composed in almost equal parts of firms of all sizes, in which service and financial firms predominate, but in which the participation, in relative terms, of the agricultural and food sectors may be highlighted. In Latin America, those countries with a degree of purchasing power such as Chile, Mexico, Peru and
Venezuela stand out, where most of the firms in this group are active, whereas the scant presence in Europe is concentrated in Italy, which is somewhat logical if similarities between the foodstuffs consumed in both countries are taken into account.

\subsubsection{Group 5 (57 records)}

This group is characterized by firms of a large size that, as in the previous group, are principally from the financial, agricultural and food sectors. However, their locations are radically different. The UK stands out in Europe, as the European financial heartland, whereas the target countries are smaller and less economically developed in Latin America; principally Costa Rica, Ecuador and Nicaragua.

\subsubsection{Group 6 (3 records)}

This is the least numerous group in the entire mapping, from which no conclusions may be drawn with respect to the characteristics of its constituent firms, which are considered special cases, in the same way as those in group 3 .

\subsubsection{Group 7 ( 88 records)}

The principal feature of this group is the absence of large-sized firms, as the group is solely composed of firms in the first three quintiles of a population ordered from small to large, and fundamentally of firms in the first two: the two main sectors being principally services and manufacturing.

The Latin American presence is composed almost exclusively of firms localized in Chile, whereas Portugal, the UK, the Netherlands and Belgium are prominent in Europe, and the presence of Nordic countries - Denmark and Finland - are also relevant. It therefore appears that the strategy of these firms consists in seeking out developed countries in which to carry out their businesses activities under the most stable possible conditions.

\subsubsection{Group 8 (214 records)}

This is the second most numerous group in the SOM mapping, with a below-average size, the principal references for which are the manufacturing and services sector. The presence in the American continent is very well distributed, both in large and in small countries, and with relatively low and high levels of political risk. It is also distributed in Europe, although there is a slight bias here towards countries with highly developed market economies, principally Germany, France, and the UK that are references in Europe and worldwide, and also Sweden.

\subsubsection{Group 9 (105 records)}

The bias towards large-sized firms in this group is one of the most pronounced. However, its sectoral distribution is much more diversified, with wholesale and retail firms from the financial sector, as well as from the transport, communications and public services sectors. Brazil, Colombia, Paraguay and Uruguay stand out in Latin America, whereas Greece and Eastern European countries such as Poland and Slovakia predominate in Europe. Thus, it is a matter of investments with a higher risk, in countries with higher levels of political risk, though these factors might be compensated by lower levels of competitiveness and by greater potential for growth.

\subsubsection{Group 10 (36 records)}

This group is one of the most numerous in the mapping and is composed of large-sized firms. They belong to the agricultural, food and manufacturing sectors, with an almost total and notable absence of the financial and services sectors, which in principle are the most numerous. Their presence is concentrated on the one hand, in Bolivia, Brazil and Mexico and, on the other, 


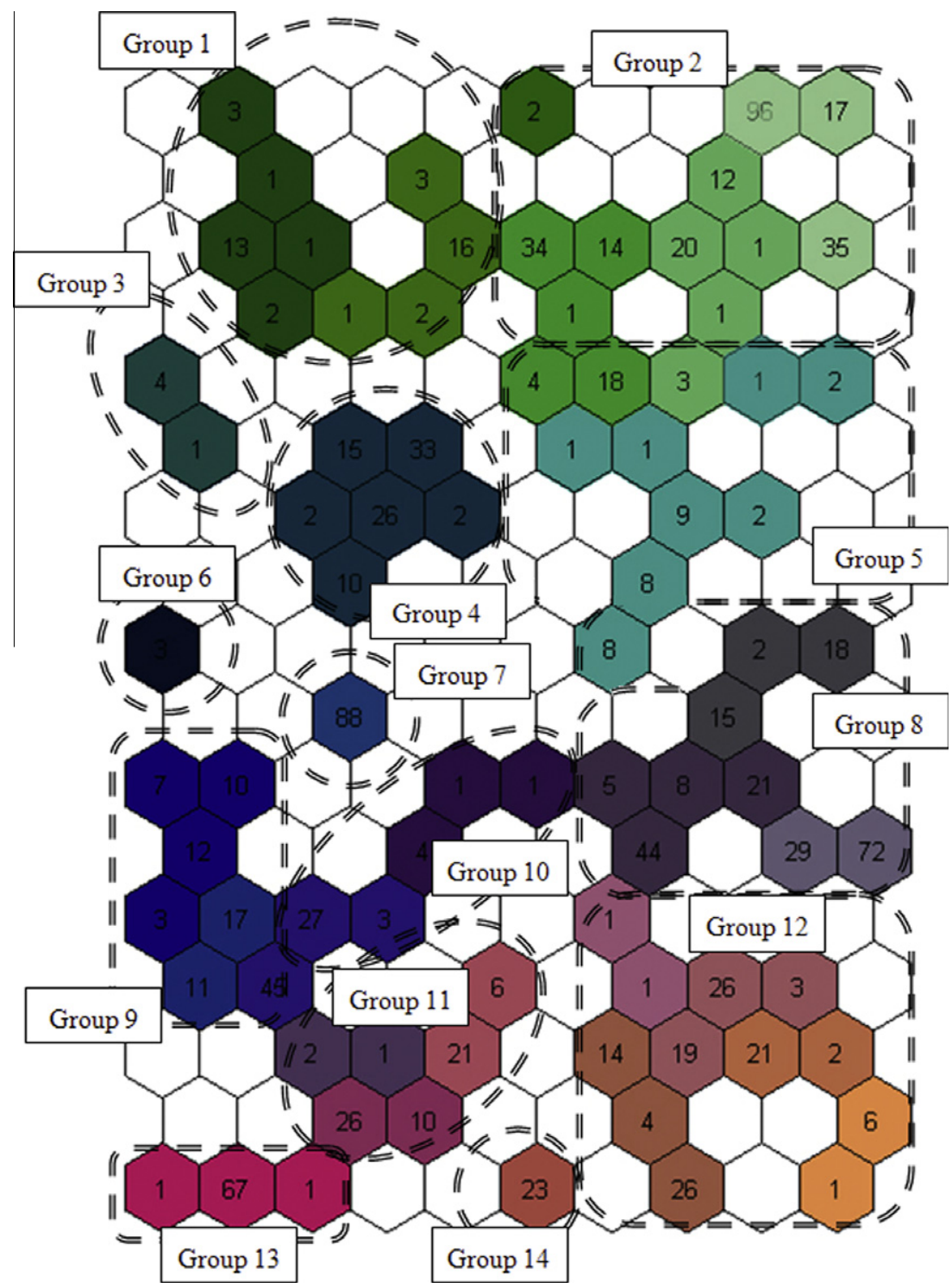

Fig. 6. SOM colored and numbered map of the Spanish MNEs dataset.

mainly in Germany. Thus, the strategy of this small group of firms appears to center on larger-sized markets.

\subsubsection{Group 11 (61 records)}

Large multinationals from the manufacturing and financial services sectors make up the greater part of this group. Italy and Mexico are the main destinations for foreign investments, clearly revealing an internationalization strategy based on minimization of the negative impact that a large cultural gap between the country of origin and the host country can have for the success of the investment.

\subsubsection{Group 12 (124 records)}

This group is composed of larger-than-average sized firms, but with a range of sizes, as there are various small-sized firms (first and second quintile), very few of a slightly larger-thanaverage size (fourth quintile) and many of a very much largerthan-average size (fifth quintile). As in group 10, the agricultural, food and manufacturing sectors predominate in the sample, although in this case such an acute absence of the other sectors is not evident, given the high number of records that make up the group. Ecuador, the Dominican Republic and Venezuela are prominent in Latin America, whereas France, Poland, Portugal and the UK are prominent in Europe. Two different investor strategies may be appreciated in this group: those that seek low salary costs for manufacturing purposes in Latin-American countries and Poland, and those that seek a market share in developed countries where they can successfully launch their products in European countries that are not so far away from Spain.

\subsubsection{Group 13 (69 records)}

A pronounced bias towards smaller-than-average size service sector firms may be seen in group 13. The Spanish MNEs in this group are found in small Latin American countries with higher levels of risk, namely El Salvador, Honduras, Peru and new members of the European Union from "Eastern Europe" such as Poland, Hungary and the Czech Republic. This exceedingly risky internationalization strategy is due to their smaller size thanks to which they can adapt with greater ease to the business setting and take advantage of lower sinking costs that may never be recouped in case of divestment. 


\subsubsection{Group 14 (23 records)}

Finally, the last group is the smallest of the mapping (excluding the two special cases) and its composition is evenly distributed between small and large-sized firms. With the exception of one firm from the manufacturing sector and two from the telecommunications and public services sectors, the group is solely composed of financial and services-sector firms. A European presence is almost inexistent, as only two subsidiaries are found in Italy, whereas the presence in Latin America is concentrated in Colombia, well in front of El Salvador, Ecuador and Mexico.

\subsection{CCA projection}

Fig. 7 presents the CCA projection. CCA was unable to display the inner structure of this dataset, and could only differentiate two main groups. The parameter values that generated this projection were: cityblock distance, lambda $=168,850$ (default value), alpha $=0.5$ and 5 epochs.

As can be seen in Fig. 7, CCA provides a main cloud containing most of the data, and simultaneously a smaller one above the main cloud. A full description of this projection is not provided as it is not given too much information about the internal structure of the dataset.

\subsection{Discussion and conclusions for the Spanish MNEs case study}

This case study has brought to light the different reasons for which Spanish MNEs internationalize and the way they pursue different goals, which may be appreciated in the above projections. These MNEs set up in a particular country according to their specific needs or those of their sector, as it is evident from the different groups identified by CMLHL.

The projection of groups generated by the SOM has shown different internationalization strategies that are put into practice by Spanish MNEs, principally in accordance with their size, the sector to which they belong and the motivation that led them to choose a particular country in which to target their investment.

However, it may be appreciated from a comparison between the results generated by this approach and those generated by CMLHL that the latter technique displays a more easily interpretable projection of the different groups, allowing more studied conclusions to be drawn based on a more homogeneous internal group structure, with clearly differentiated external structures.

Thus, the SOM has on some occasions enabled risk-aversion strategies to be perceived and, on other occasions, versatile strategies that adapt to unfavorable business settings. However, some groups include subsidiaries localized in various countries with different strategies. In contrast, the internationalization strategies brought to light by CMLHL may be more clearly appreciated, even those that are more complex. Examples include certain strategies that lead companies to set up in countries with higher levels of political risk, where they can use their negotiating skills to gain competitive advantages from local government bodies with extensive discretional powers or in countries with corrupt systems, which is consistent with recent findings (Jiménez et al., 2011; García-Canal \& Guillén, 2008; Holburn, 2001) that had previously identified a proactive use of political risk in the internationalization strategy of firms under certain circumstances. Other company strategies target Eastern European countries because of their potential for growth and stability, thanks to their institutional development and recent entry into the European Union (Bevan \& Estrin, 2004; Wheeler \& Mody, 1992), and yet others are mainly guided by cost reductions and greater efficiency, among other considerations. Furthermore, the subgroups that this technique has revealed, with similar strategies but with certain differentiating characteristics, enrich the conclusions that may be drawn and help to understand the complex internationalization strategies of Spanish firms.

CMLHL (Figs. 2-4) generates a clearer and more widely spread mapping than PCA (Fig. 1), SOM (Figs. 5 and 6), and CCA (Fig. 7). It extracts more visual information, which in turn enables clearer and better conclusions to be drawn from the data.

In brief, it may be concluded that this study has revealed a range of different reasons underlying the internationalization strategies of Spanish MNEs and the different goals they pursue. This may be appreciated from the different groups identified by CMLHL, which show enterprises localizing in a specific country according to their specific needs or those of their sector, as is evinced by the different subgroups.

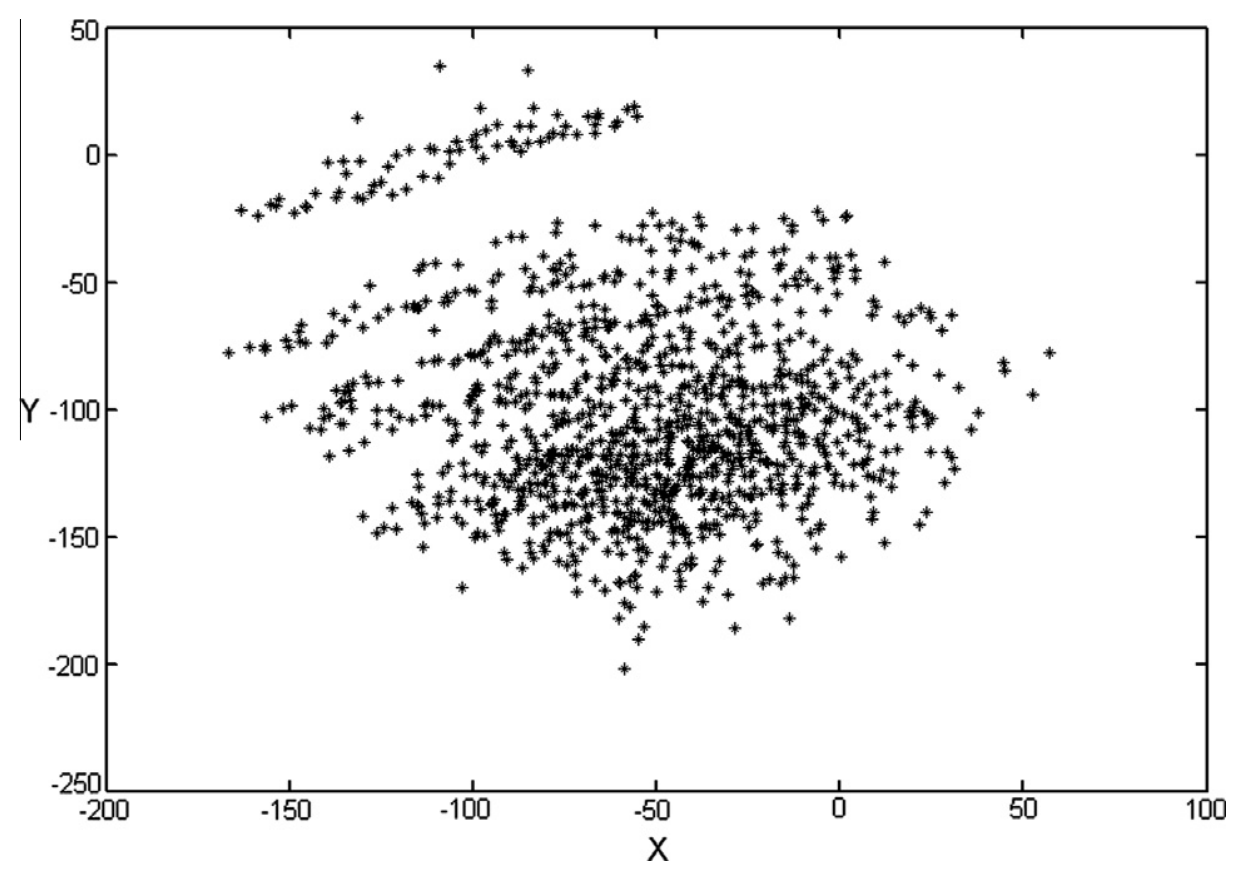

Fig. 7. CCA projection of the Spanish MNEs dataset. 


\section{The Risk Briefing case study}

The Risk Briefing dataset (Risk Briefing, 2009), which is maintained by the Economist Intelligence Unit, tracks the scores of 158 countries for 10 categories of risk: security, political stability, government effectiveness, legal and regulatory, macroeconomic, foreign trade and payments, financial, tax policy, labor market, and infrastructure.

These categories, updated once a quarter, provide an assessment of different aspects of country and political risk by covering, among others, the financial, macroeconomic, fiscal, labor and political environment. They range from 0 to 100 , where 100 refers to the riskiest country in the selected category.

As asserted by the authors, this dataset is designed to assist investors assess and plan in view of the risks of doing business around the world, providing comprehensive and timely analysis, forecasts, alerts, background studies, and data covering a wide range of risk factors. The dataset is generated by a global network of over 650 correspondents and analysts who monitor world events and assess their impact on business.

As some of the risk categories are highly correlated, it was decided to remove six of them with a high correlation index. As a result, only four categories (security, macroeconomic, tax policy, and labor market) were included in the dataset for such case study.

\subsection{PCA projection}

Fig. 8 presents the PCA projection onto the two first principal components. As may be seen, PCA is able to identify 11 different groups as described below.

\subsubsection{Group 1: 30 countries}

Low levels of below the average tax policy and labor market risk, and especially low levels of security risk are key features of this group. In this latter case, moreover, the scores are the lowest of the whole sample. These are characteristics of developed countries which are political and institutionally stable such as United States, France, Germany, Canada, Norway or Holland. However, due to the present global crisis and the multiple interlinkages of the international economy, these countries suffer from very high levels of macroeconomic risk, definitely over the average. However, this group also includes a few new members of the European Union, such as Slovakia, Slovenia, Czech Republic, Latvia or Lithuania which are geographically close to other economies of this group and whose accession to this supranational body has lead to improvements in their economic and institutional development. However, it is still too early to affirm that the aforementioned countries share the very same features towards their risk profile and can be included within the same group with the other economies.

\subsubsection{Group 2: 15 countries}

Countries in this group, where Turkey, Argentina or Russia can be found, show slightly over the average security, tax policy and labor market risk levels. The institutional development and the political stability of the countries are lower than they were in the previous group. However, macroeconomic risk levels are lower because these economies are less integrated in the international economic context.

\subsubsection{Group 3: 43 countries}

Group 3 is formed by developing countries, some of them relatively advanced such as Mexico, Brazil, Vietnam, Malaysia, Egypt, Romania or Croatia, and others not so much like Armenia, Moldova, Namibia, Iran or Albania. Here, institutional development is deficient, which provokes high security risk levels. They are also politically unstable, with frequent changes in national policies that affect taxation and labor market and increase risk levels. However, their greater development compared to other developing economies and international linkages with other economies increase their relative exposure to the present global crisis rather more than might be expected at first, which explains their higher macroeconomic risk scores. It is worth highlighting that this group includes Italy and South Korea, countries that appear to fit less with other elements of the group, and more so with the other group of more developed countries.

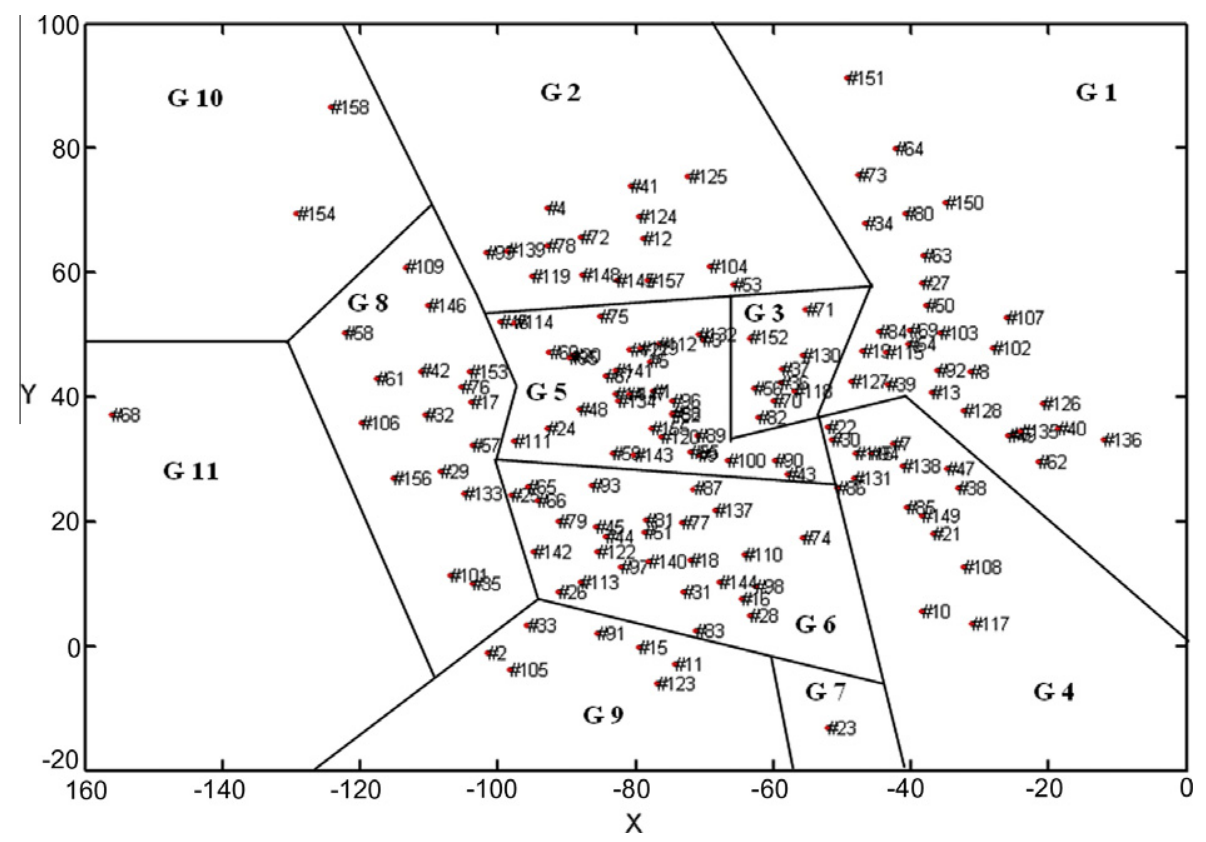

Fig. 8. PCA projection of the Risk Briefing dataset. 


\subsubsection{Group 4: 16 countries}

These countries have below average risk levels for all the different aspects of risk analyzed in this paper. Scores are especially low in the security and tax policy risk categories, and closer to the average in the other two. This fact shows that countries are also developed but to a lesser degree than those of group 1 (i.e. Spain, Portugal, Chile, Australia or even to a lesser extent those more developed countries from the Middle East such as Bahrain, United Arab Emirates or Qatar). They represent a group of countries that are attractive for international investors seeking political stability in order to minimize the risk they face when exploiting the full potential of business opportunities in developed countries.

\subsubsection{Group 5: 32 countries}

The sixth group is made up by developing countries with few links to the international economy. This allows them to obtain lower macroeconomic risk levels in the context of a global crisis. One of the scarcer linkages comes from the oil market, since some of these countries are producers and exporters, which provides them with a constant flow of income to finance their imports. Their levels of tax policy and labor market risk are above average. One of the reasons is that their governments wield highly discretional powers and face low restrictions (i.e. China, Libya, Morocco, Jordan, Kuwait, Bhutan or Syria). However, in order to maintain themselves in power and avoid international pressures, security risk levels are kept at an intermediate level, in an attempt to offer an image of a safe location for possible international investors.

\subsubsection{Group 6: 21 countries}

Group 6 is characterized by countries with a very low level of development such as Honduras, Kenya, Nigeria, Sudan, Bolivia, Colombia or Pakistan. Their governments are fragile and unstable, and offer few guarantees their commitments with regard to policies on taxation or the labor market will be upheld, increasing the risk associated with those two aspects. In addition, their economies depend heavily on other developed countries, for instance because they regularly buy their export products. Ever since the present global crisis has reduced international trade, exports have been dramatically reduced, which has increased macroeconomic risk.

\subsubsection{Group 7: 1 country (Iraq)}

This group can be considered a special case. As a country experiencing strong political instability, its situation differs radically from any other country in the sample.

\subsubsection{General conclusions}

In conclusion, PCA has been able to differentiate, with an acceptable degree of precision, between the 158 countries in the sample, one group formed by the principal economies in the world and another one that also includes developed countries but which lags a little bit behind the first group. They are characterized by strong institutional development and high political stability, which translate into low security, labor market and tax policy risks. It has also identified groups of developing countries, differentiating between those with a higher exposure to the international crisis, either because they are emergent countries or because they are dependent on a developed economy that buys their exports, and those with low political stability and institutional development, which suffer higher levels of risk in several ways. However, in the present situation of international crisis, their macroeconomic risk level is low because they are hardly integrated in the international economy at all. It should not be overlooked that once the crisis abates, which may be expected in the near future, this risk will increase at the same time as it will decrease in the other countries. Therefore, it is advisable for these economies to institute measures that will make progress in economic, social and institutional development, in order to reduce the previously described risks and become attractive destinations for national and international investments. This way, higher standards of living will be achieved through higher income, wealth and lower unemployment.

However, the groups identified by PCA offer, on certain occasions, controversial results when countries are included in the same group that have some kind of connection with the other individual countries but also have remarkable differences which suggests that they should not be catalogued within the same group. For instance in Group 1, where countries from Central and Eastern Europe, geographically close and recently integrated in the European Union, are included in the same group as the principal economies in the world. The same may be said of Group 3 where South Korea and Italy are included in a group with much less developed countries.

\subsection{CMLHL projection}

The following CMLHL projections (Figs. 9 and 10) reflect the different groups of countries obtained with this neural model. These projections were obtained by applying the following values to the different parameters of CMLHL: number of iterations $=600$, learning rate $=0.064, p$ parameter $=1.4$, and $\tau$ parameter $=0.3$.

Fig. 9 depicts all the possible combinations of the third first factor pairs obtained through CMLHL by means of a scatter plot matrix. Factor pairs under the diagonal provide no extra information.

The main result obtained by CMLHL (factor pairs 1-2 from Fig. 9) is analyzed in depth in this section.

\subsubsection{CMLHL factor pair $1-2$}

The groups identified in the CMLHL factor pair 1-2 analysis (Fig. 10) are described as follows.

5.2.1.1. Group 1: 15 countries. Some of the most important economies in the world are included in the first group, such as the United States or France, with other highly institutionally developed countries which include Denmark and Sweden. Comparing this case to group 1 in the PCA projection (Fig. 8), it can be seen that the CMLHL group is more homogeneous and selective, without the drawback of including additional economies such as the new members of the European Union, which despite the fact of being geographically close to other European economic dominant countries, still differ greatly with regard to risk levels.

5.2.1.2. Group 2: 49 countries. Group 2, which can be found very close to group 1 , is also formed by developed countries, all of which have low levels of security, labor market and tax policy risk, but with slightly lower macroeconomic risk than the previous group. The composition is a little bit varied, ranging from Germany, Spain and Canada, to the new members of the European Union and even some of the most developed countries from Asia, namely Japan, and the United Arab Emirates. Anyway, the logic of this group is to invest in developed economies or those that are close to being so, with acceptable levels of economic, political and institutional development, but with a lower exposure to macroeconomic risks according to their scores.

5.2.1.3. Group 3: 53 countries. Group 3 shows many developing countries, with a clearly inferior development to those from groups 1 and 2, which translates into higher levels of security, labor market and tax policy risk, but also lower macroeconomic risk. It is worth pointing out that within the sample of developing countries, this group includes those relatively more developed countries, which is the case of Mexico, Russia, Brazil and Argentina. 

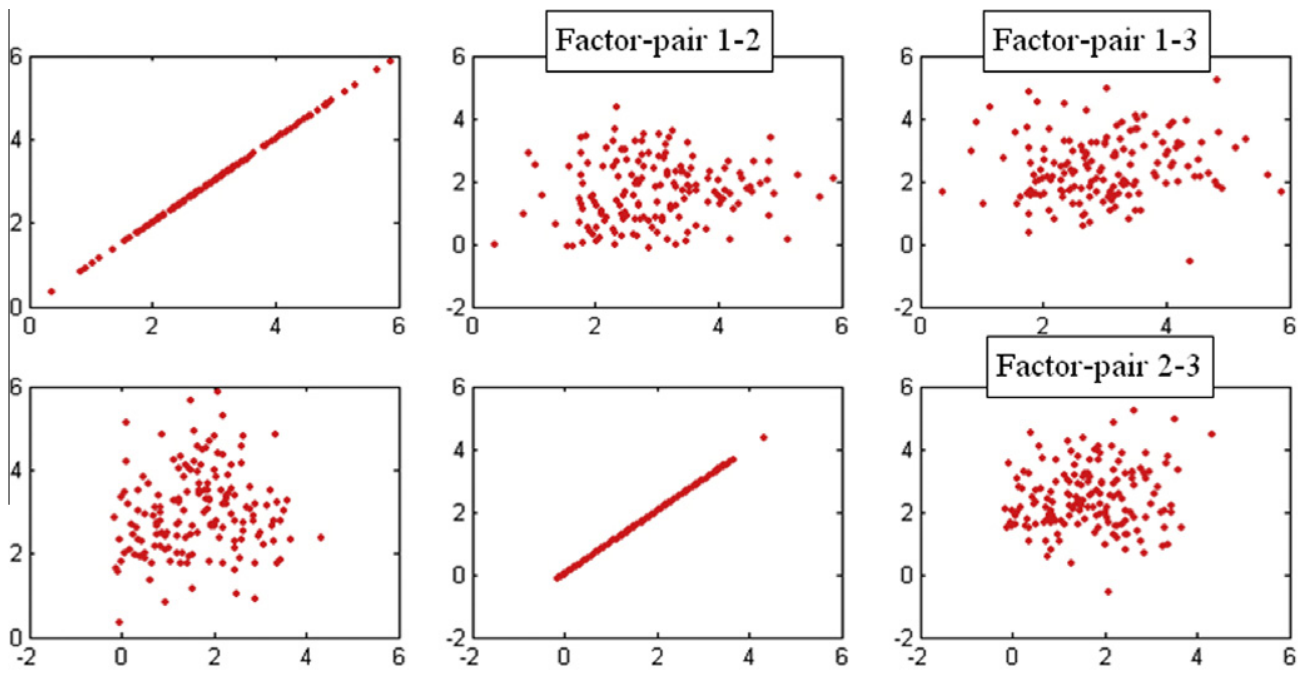

Factor-pair 2-3
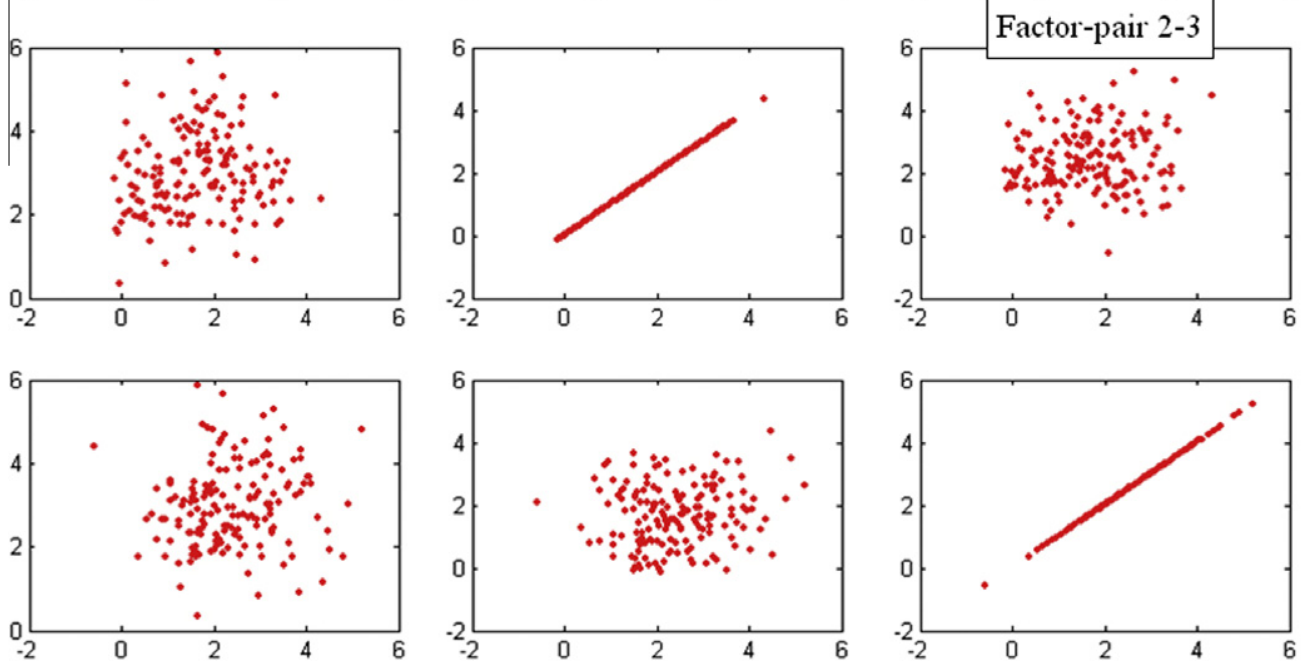

Fig. 9. CMLHL scatter plot matrix for the Risk Briefing dataset.

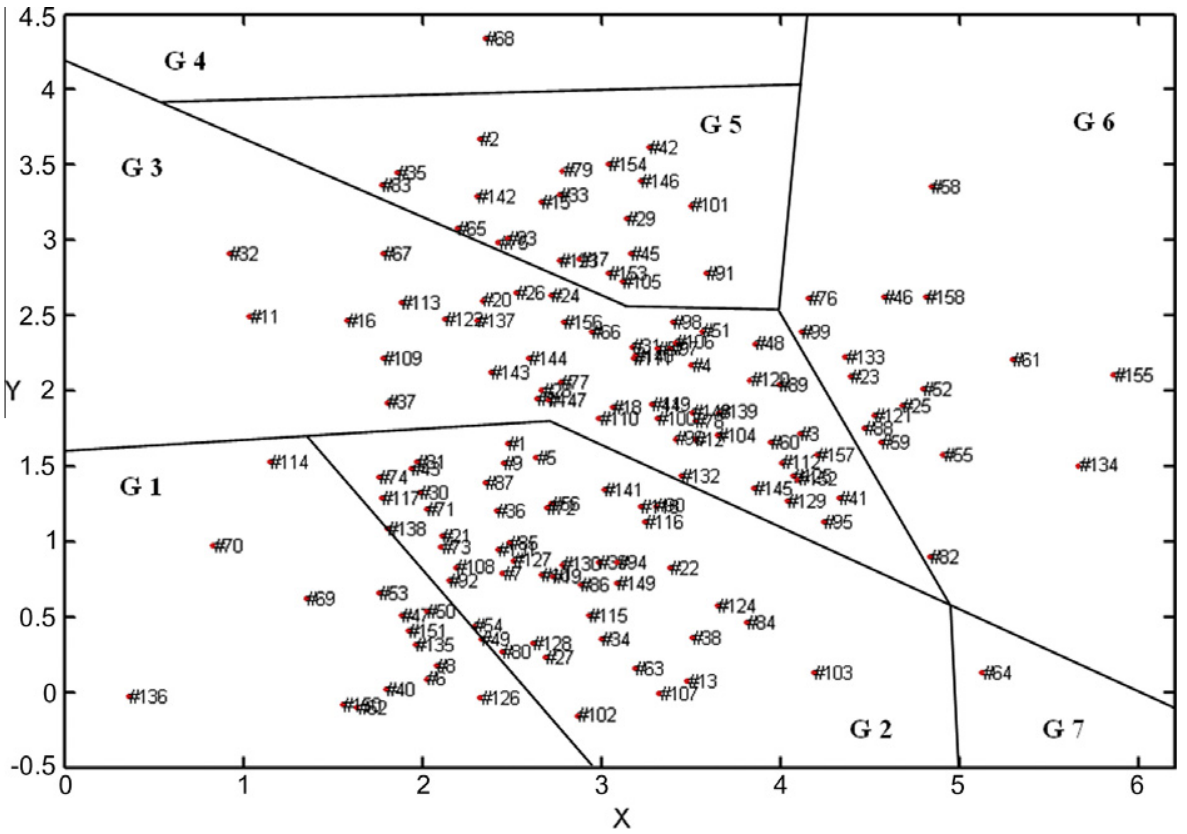

Fig. 10. CMLHL factor pair 1-2 for the Risk Briefing dataset.

5.2.1.4. Group 4: 1 country (Iraq). This technique also considers this group to be a special case. As a country experiencing strong political instability, its situation differs radically from any other country in the sample.

5.2.1.5. Group 5: 21 countries. This group is characterized by developing countries that are less advanced than those of the previous group, such as Ecuador, Libya, Senegal, Congo, Bolivia, Chad or Ivory Coast. Therefore, risk levels are higher in all aspects except for the macroeconomic. This is due to their less important role in the international economy which implies less exposure to the global crisis.

5.2.1.6. Group 6: 18 countries. The last of the groups comprises several African and Asian countries such as Kenya, Lesotho, Cambodia, Madagascar, Zimbabwe, Ghana or Gambia with a very high risk profile due to their low economic and institutional development and their political instability. However a remarkable difference with the countries of group 5 can be pointed out: while in the pre- 
vious group macroeconomic levels were the lowest in the whole sample, in this case the levels are around the average, showing a relatively higher exposure to the crisis, probably due to the dependence of revenues coming from another economy through exports, as was also the case for PCA group 6.

5.2.1.7. Group 7: 1 country (Iceland). The group can be considered a special case. CMLHL has been able to distinguish a country with unique characteristics. Despite the fact that the country only has 300,000 habitants, Iceland's economy achieved spectacular growth over recent years, becoming an important finance center in the world and one of the countries with the highest per capita income. However, it is also one of the countries that is suffering the consequences of the present crisis more than any other, with several multinational companies even leaving the country without any plans to return in the near future. The CMLHL projection (Fig. 10) shows this situation perfectly, as Iceland is not far away from group 2, showing a country that was on the road to becoming a solid developed country but which faces grave problems at present. In fact, security and tax policy risk are very low but the macroeconomic risk is extremely high.

5.2.1.8. General conclusions. In conclusion, this technique has been able to differentiate five principal groups, two of which include developed countries and three include developing countries. Group 1 includes those developed countries that are more affected by the present crisis while group 2 includes those with a relatively lower exposure but which are also less strict about the requirements which define an economy as developed. Among the three groups that include the developing countries, group 3 includes those that are relatively more advanced, while groups 4 and 5 include those that are relatively less so. The former group is characterized by countries with a lower macroeconomic risk and the latter by countries with a higher level. In all of them, but especially in the last case, it is important once again to underline the need for structural measures in order to improve the situation, promoted by both local authorities and international bodies.

CMLHL clustered the countries from the sample in fewer groups (excluding special cases), but they have a clearer, more refined and logical composition than those obtained by PCA (Fig. 8) where a group sometimes includes countries with a common characteristic but with also big differences which leads one to think that they should belong to different groups. This was the case for the new members of the European Union and also for Italy and South Korea. PCA (Fig. 8) included Iceland, a country where incredible growth rates were achieved in a short time ago, but which nowadays faces the disastrous consequences of a deep crisis, in Group 1, due to its low security and tax policy risk levels. However, CMLHL has been much more precise, differentiating this economy from the rest of countries in the sample.

\subsection{SOM mapping}

As for the Spanish MNEs dataset, the SOM mapping of the Risk Briefing dataset is visualized by means of:

$U$-matrix (Fig. 11): distance matrix between the reference vectors of adjacent neurons in the two-dimensional lattice.

- Numbered map (Fig. 12): neurons in the rectangular lattice were labeled with a figure that represented the number of companies associated with each neuron. To ease the analysis of this result, neurons were grouped according to their location on the map. Additionally, to make this mapping more intuitive, neurons were colored following a topological ordering.

These results are analyzed in the following paragraphs. The parameter values that generated this mapping were: random ini-

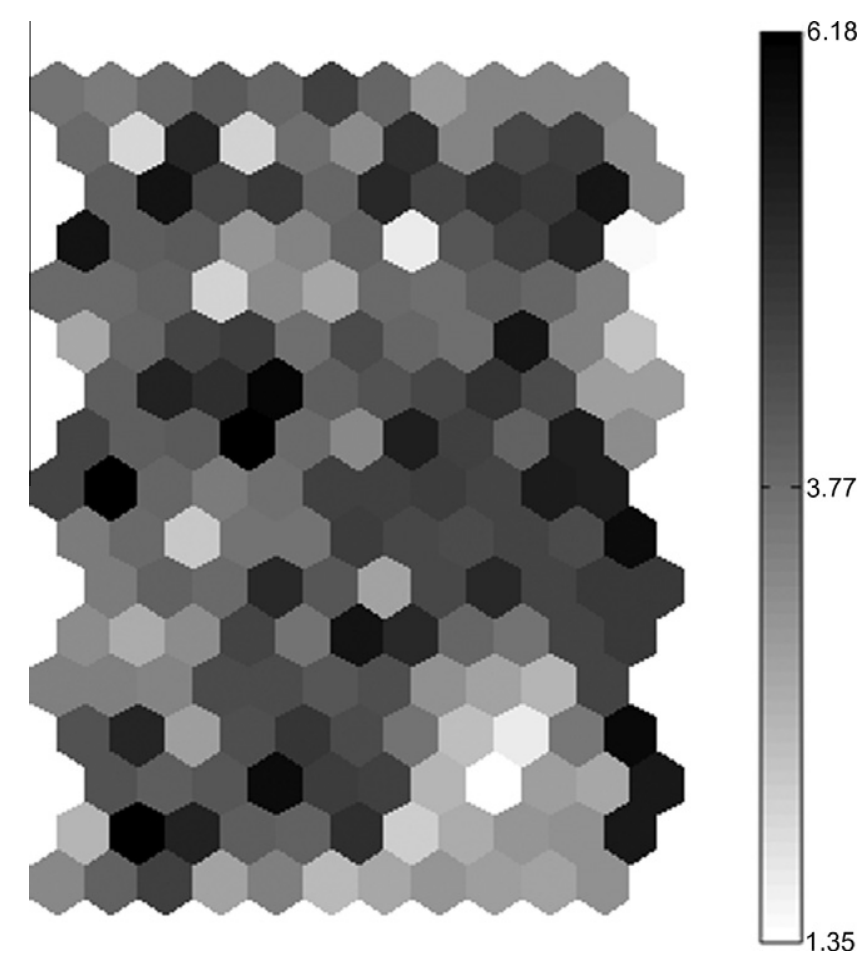

Fig. 11. SOM $U$-matrix of the Risk Briefing dataset.

tialization, sequential training, hexagonal lattice, Gaussian neighborhood function. The grid size was fixed to $9 \times 6$ by means of a heuristic formula.

\subsubsection{Group 1: 25 countries}

This group includes several countries with very low security and tax policy risk levels, around average labor market and very high macroeconomic risk levels such as Israel, Australia or Portugal. However, there are some others which do not seem to fit these characteristics. For example, security risks in Philippines, Georgia or Venezuela are extremely high, while macroeconomic risk in Burkina Faso or Qatar has lower macroeconomic risk than those developed economies.

\subsubsection{Group 2: 13 countries}

Group 2 includes countries with slightly below average risk levels in all the different aspects analyzed. This means that their institutional and economic development and their exposure to the crisis are intermediate, as happens in Jordan or Bulgaria. Again, there are some elements that, either because they have a much lower macroeconomic risk (Bangladesh and Senegal) or a much higher degree of development (Spain), do not seem to fit well with the rest of countries in the group.

\subsubsection{Group 3: 5 countries}

Group 3 is formed of the countries with the highest levels of security, labor market and tax policy risk. Iraq, Honduras or Yemen are locations where the risk that companies face is so high that investments are advised against unless they provide a very high rate of return.

\subsubsection{Group 4: 23 countries}

In contrast, group 4 includes some of the most advanced economies such as France, Germany, Norway or Canada, where levels of risk are very low except for macroeconomic risk. Once again, the group is not completely homogeneous, since countries 


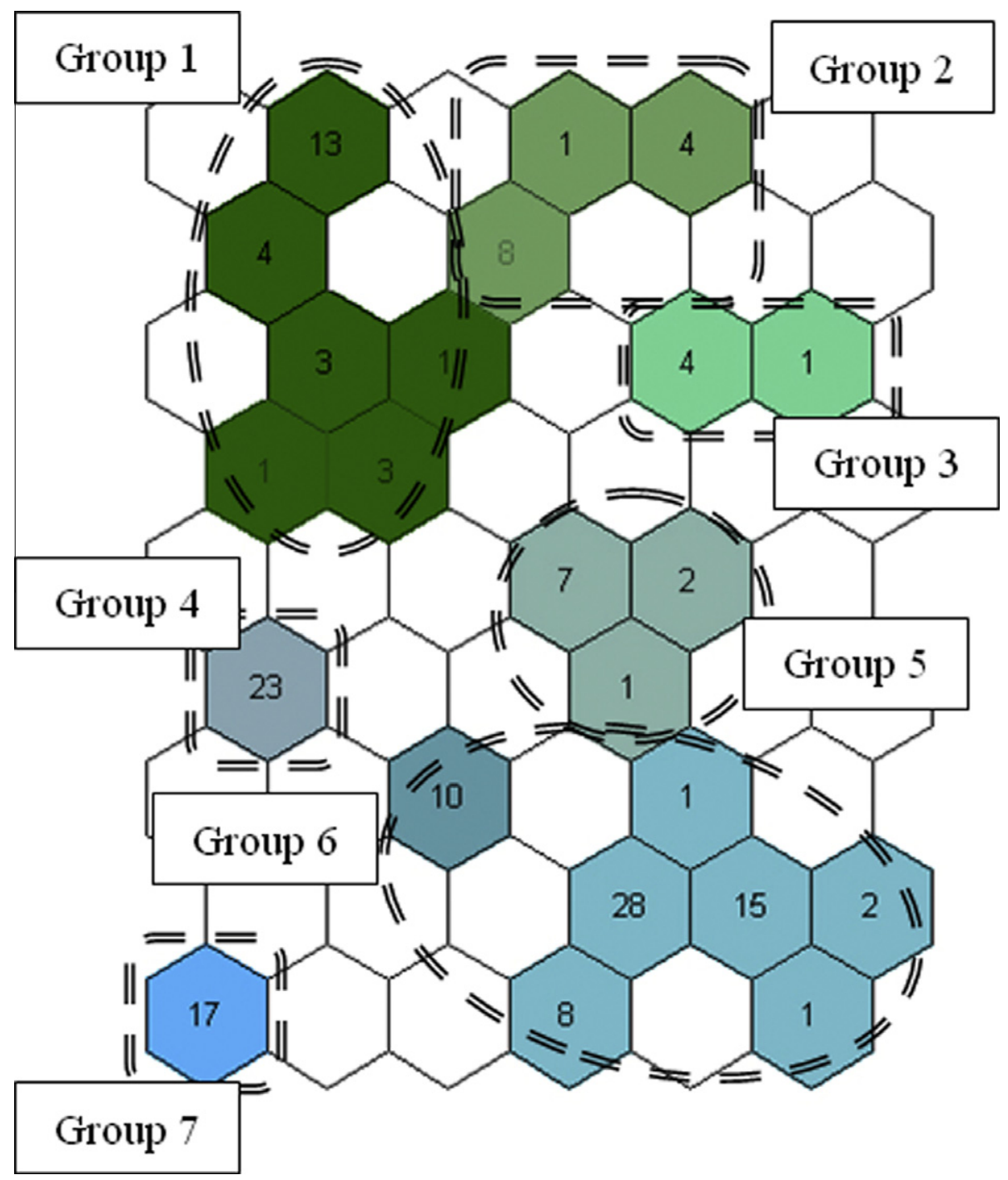

Fig. 12. SOM colored and numbered map of the Risk Briefing dataset.

with different characteristic such as Iceland, Cuba or Botswana, are also included.

\subsubsection{Group 5: 10 countries}

High levels of macroeconomic risk are a key feature of group 5 , derived from the high dependence from developed economies that are suffering the present crisis. However political and institutional development is not very advanced, which leads to high scores in the other risk aspects too. This is the case of Ecuador, Argentina or Kazakhstan. Strangely, it also includes two other countries with much lower security, tax policy and labor market risk: the United States and the UK.

\subsubsection{Group 6: 65 countries}

Group 6 has the most countries by a wide margin. It is made up of developing countries, both those which can be considered emerging economies such as Brazil, Turkey and China, and those that are less advanced, such as Sri Lanka, Zambia, Lesotho, Gambia and Ethiopia.

\subsubsection{Group 7: 17 countries}

Finally, the last group also includes developing countries - for instance, Burundi, Congo, Togo and Tanzania - with high scores in security, tax policy and market labor risks. However, in this case, their degree of development is the lower in the sample and their international linkages almost non-existent, which leads to low exposure to the crisis and therefore to low macroeconomic risk levels.

\subsubsection{General conclusions}

In conclusion, the SOM has offered overall results that are worse than the preceding two. The conclusions that may be drawn tend to point in the same direction, since groups are formed mainly either by developed or developing countries, depending on their exposure to macroeconomic risk and degree of economic, political, social and institutional development. However the SOM technique has offered results with several inconsistencies. Countries with different characteristics were included in the same group on certain occasions. Also, it was not possible to distinguish between different types of developing countries, since emerging and less advanced developing economies were included in the same group. Finally, special cases such as Iceland and Iraq were not isolated from the other countries, in spite of the very unusual situations they are undergoing.

\section{4. $C C A$}

Fig. 13 presents the CCA projection of the Risk Briefing dataset. The parameter values that generated this projection were: stan- 


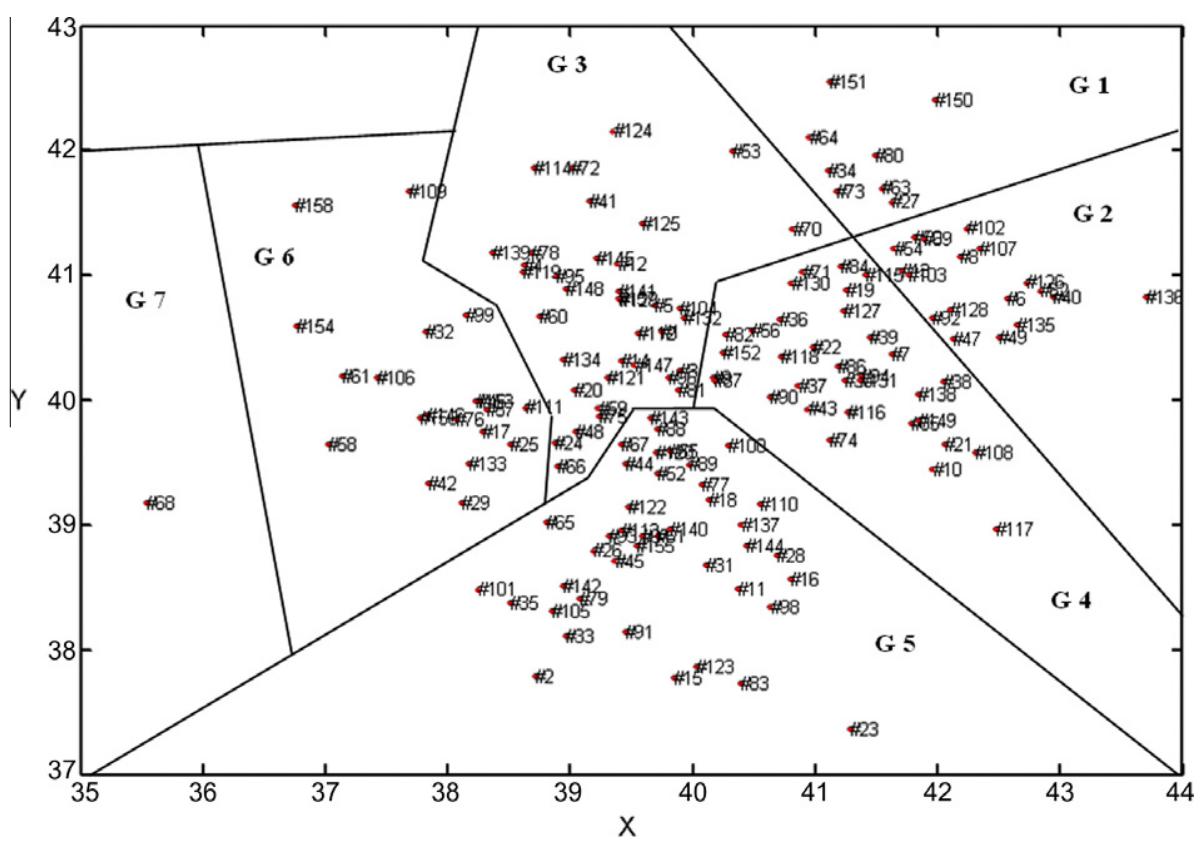

Fig. 13. CCA projection of the Risk Briefing dataset.

dardized Euclidean distance, lambda $=160,000$, alpha $=0.4$ and 7 epochs.

The groups identified in the CCA projection can be described as follows:

\subsubsection{Group 1: 8 countries}

Group 1 includes global economic powers such as the United States, Japan, Canada and the UK which, as previously described, are characterized by high levels of institutional development and political stability, but also by a high exposure to the international crisis. However, this group also includes countries that do not share all those features, for instance Latvia and Costa Rica. Also in this group, the technique has not been able to differentiate the particular situation of Iceland, country that was starting to achieve a relatively advanced level of development but is now experiencing the worst consequences of the crisis.

\subsubsection{Group 2: 18 countries}

Group 2 also includes many developed countries, but with a relatively lower level of exposure to the crisis. Therefore, risk levels are very low in every single aspect except for the macroeconomic risk. In addition, this group is quite homogeneous, including countries such as Belgium, France, Finland, Germany, New Zealand, Norway and Switzerland.

\subsubsection{Group 3: 37 countries}

This group is the first that is mainly composed of emerging countries. However, it includes emerging countries with a more advanced development (i.e. Brazil, Turkey, Mexico or Russia) as well as others that lag some way behind such as Zambia, Uganda, Burundi or Sri Lanka.

\subsubsection{Group 4: 33 countries}

Different and heterogeneous countries are included in Group 4. More precisely, developed economies such as Australia, Spain, South Korea, Portugal and Italy are in the same group as emerging economies from Central and Eastern Europe (i.e. Poland, Slovakia or Czech Republic) and even some developing countries, such as Macedonia, Botswana or Azerbaijan.

\subsubsection{Group 5: 41 countries}

Countries with a low level of economic and institutional development and a high political instability, such as Ivory Coast, Gabon, Burkina Faso, Rwanda, Senegal, Togo, Namibia or Equatorial Guinea, comprise Group 5. Therefore, security, labor market and tax policy levels are high, while their low macroeconomic risk levels come from their low exposure to international risk given their almost non-existent connections with the international economy.

\subsubsection{Group 6: 20 countries}

As in the previous case, this group includes countries characterized by low levels of economic and institutional development, and high political instability, but with relatively higher levels of macroeconomic risk, resulting from their dependence on a developed economy affected by the crisis. For instance, Honduras, Ecuador, Colombia or Pakistan share these features.

\subsubsection{Group 7: country (Iraq)}

This technique also identifies this group as a special case. As a country experiencing strong political instability, its situation differs radically from any other country in the sample.

\subsubsection{General conclusions}

Once again, the CCA technique has been able to differentiate groups according to their level of economic and institutional development. The first two groups include the majority of the developed countries while developing countries comprise groups 4, 5 and 6 . However, the composition of the groups has not been as homogeneous as expected, and group 3 is a good example of this, because it includes developed, emerging as well as developing countries.

\subsection{Discussion and conclusions for the Risk Briefing case study}

In the Risk Briefing case study, the four different techniques (CMHL, PCA, SOM and CCA) used to analyze several aspects of risk associated with possible locations for foreign direct investments, have offered similar results, showing the consistency and robustness of the conclusions that may be extracted from them.

In general, countries are distributed into groups with similar levels of economic, political and institutional development. In fact, 
evidence suggests the existence of a different structure between developed and developing countries. Furthermore, within the group of developed countries, characterized by low levels of security, labor market and tax policy risk, two different sub-groups can be distinguished, according to their exposure to the present international crisis, which leads to different levels of macroeconomic risk.

On the other hand, developing countries have also been included in different sub-groups depending on their relative degree of development, their dependence on other developed economies and their isolation from the international economy, which therefore have a lower level of macroeconomic risk due to their lower exposure to the crisis.

However, the four projection techniques have offered results which differ in their accuracy and precision. On one hand, some of the sub-groups obtained with the CCA and SOM techniques are characterized by certain heterogeneity, since they include developed, emerging and developing countries. Moreover, both PCA and CMLHL offer much clearer and more homogeneous results. In fact, even though they all identified the particular situation of Iraq, as a country experiencing strong political instability, the CMLHL results picked out the special case of Iceland, showing the high level of detail and the precision of its results.

\section{General conclusions and future work}

In general terms, it may be concluded that the projection models in general, and CMLHL in particular, are able to visualize and describe the situation of international companies and countries within the framework of political and country risk. This information is especially valuable to investors in a context of higher uncertainty derived from the global crisis. In fact, having access to reliable tools to provide clear, relevant and updated information to decisionmakers can be an important source of competitive advantage both to managers in MNEs and policy-makers in countries.

Future work will widen the international focus of the study to other areas and companies, for example from a different home country or to specific sectors where the institutional environment is more likely to have a greater impact on the location strategy (i.e. "regulated-sectors" such as banking or telecommunications) Also, other unsupervised neural models will be applied, for comparison purposes, to these interesting case studies.

\section{Acknowledgments}

Alfredo Jiménez Palmero is grateful for the financial support from the Spanish Ministry of Science and Innovation through the FPU programme. This research has been partially supported through the Junta of Castilla and León under project BU006A08; the Spanish Ministry of Education and Innovation under project CIT-020000-2008-2 and CIT-020000-2009-12. The authors would also like to thank the vehicle interior manufacturer, Grupo Antolin Ingenieria S.A., under project MAGNO2008-1028.- CENIT Project funded by the Spanish Government.

\section{Appendix A}

See Table 1.

Table 1

Country list and codes for the Risk Briefing dataset.

\begin{tabular}{|c|c|c|c|c|c|c|c|}
\hline \#1 & Albania & \#22 & Bulgaria & \#43 & Egypt & \#64 & Iceland \\
\hline \#2 & Algeria & \#23 & Burkina Faso & \#44 & El Salvador & \#65 & India \\
\hline \#3 & Angola & $\# 24$ & Burundi & \#45 & Equatorial Guinea & \#66 & Indonesia \\
\hline$\# 4$ & Argentina & \#25 & Cambodia & \#46 & Eritrea & \#67 & Iran \\
\hline \#5 & Armenia & \#26 & Cameroon & $\# 47$ & Estonia & \#68 & Iraq \\
\hline \#6 & Aruba & $\# 27$ & Canada & $\# 48$ & Ethiopia & \#69 & Ireland \\
\hline \#7 & Australia & \#28 & Cape Verde & \#49 & Finland & \#70 & Israel \\
\hline \#8 & Austria & $\# 29$ & Chad & \#50 & France & \#71 & Italy \\
\hline \#9 & Azerbaijan & \#30 & Chile & \#51 & Gabon & \#72 & Jamaica \\
\hline \#10 & Bahrain & \#31 & China & \#52 & Gambia & \#73 & Japan \\
\hline \#11 & Bangladesh & \#32 & Colombia & \#53 & Georgia & \#74 & Jordan \\
\hline \#12 & Belarus & \#33 & Congo & \#54 & Germany & \#75 & Kazakhstan \\
\hline \#13 & Belgium & \#34 & Costa Rica & \#55 & Ghana & \#76 & Kenya \\
\hline \#14 & Belize & \#35 & Côte d'Ivoire & \#56 & Greece & \#77 & Kuwait \\
\hline \#15 & Benin & \#36 & Croatia & \#57 & Guatemala & \#78 & Kyrgyz Republic \\
\hline \#16 & Bhutan & \#37 & Cuba & \#58 & Guinea & \#79 & Laos \\
\hline \#17 & Bolivia & \#38 & Cyprus & \#59 & Guyana & \#80 & Latvia \\
\hline \#18 & Bosnia and Herzegovina & \#39 & Czech Republic & $\# 60$ & Haiti & \#81 & Lebanon \\
\hline \#19 & Botswana & \#40 & Denmark & \#61 & Honduras & \#82 & Lesotho \\
\hline \#20 & Brazil & \#41 & Dominican Republic & \#62 & Hong Kong & \#83 & Libya \\
\hline \#21 & Brunei & \#42 & Ecuador & \#63 & Hungary & \#84 & Lithuania \\
\hline \#85 & Luxembourg & \#104 & Nicaragua & \#123 & Senegal & \#142 & Togo \\
\hline \#86 & Macau & \#105 & Niger & \#124 & Serbia & \#143 & Trinidad and Tobago \\
\hline \#87 & Macedonia & \#106 & Nigeria & \#125 & Seychelles & \#144 & Tunisia \\
\hline \#88 & Madagascar & \#107 & Norway & \#126 & Singapore & \#145 & Turkey \\
\hline \#89 & Malawi & \#108 & Oman & \#127 & Slovakia & \#146 & Turkmenistan \\
\hline \#90 & Malaysia & \#109 & Pakistan & \#128 & Slovenia & \#147 & Uganda \\
\hline \#91 & Mali & \#110 & Panama & \#129 & South Africa & \#148 & Ukraine \\
\hline \#92 & Malta & \#111 & Papua New Guinea & \#130 & South Korea & \#149 & United Arab Emirates \\
\hline \#93 & Mauritania & \#112 & Paraguay & \#131 & Spain & \#150 & UK \\
\hline \#94 & Mauritius & \#113 & Peru & \#132 & Sri Lanka & \#151 & United States of America \\
\hline \#95 & Mexico & \#114 & Philippines & \#133 & Sudan & \#152 & Uruguay \\
\hline \#96 & Moldova & \#115 & Poland & \#134 & Swaziland & \#153 & Uzbekistan \\
\hline \#97 & Morocco & \#116 & Portugal & \#135 & Sweden & \#154 & Venezuela \\
\hline \#98 & Mozambique & \#117 & Qatar & \#136 & Switzerland & \#155 & Vietnam \\
\hline \#99 & Myanmar & \#118 & Romania & \#137 & Syria & \#156 & Yemen \\
\hline \#100 & Namibia & \#119 & Russia & \#138 & Taiwan & \#157 & Zambia \\
\hline \#101 & Nepal & \#120 & Rwanda & \#139 & Tajikistan & \#158 & Zimbabwe \\
\hline \#102 & Netherlands & \#121 & São Tomé and Príncipe & \#140 & Tanzania & & \\
\hline \#103 & New Zealand & \#122 & Saudi Arabia & \#141 & Thailand & & \\
\hline
\end{tabular}




\section{References}

Ahlberg, C., \& Shneiderman, B. (1994). Visual information seeking: Tight coupling of dynamic query filters with starfield displays. Paper presented at the SIGCHI conference on human factors in computing systems, Boston, Massachusetts, United States.

Avramovic, D. (1958). Debt servicing capacity and post war growth in international indebtedness. Baltimore, MD: Johns Hopkins Press.

Baruque, B., \& Corchado, E. (2010). A weighted voting summarization of SOM ensembles. Data Mining and Knowledge Discovery, 21(3), 398-426.

Bengoa, M., \& Sanchez-Robles, B. (2003). Foreign direct investment, economic freedom and growth: New evidence from Latin America. European Journal of Political Economy, 19(3), 529-545.

Bevan, A. A., \& Estrin, S. (2004). The determinants of foreign direct investment into European transition economies. Journal of Comparative Economics, 32(4), 775-787.

Brouthers, L. E., Gao, Y., \& McNicol, J. P. (2008). Corruption and market attractiveness influences on different types of FDI. Strategic Management Journal, 29(6), 673-680.

Chen, S.-H., \& Huang, Y.-C. (2007). Relative risk aversion and wealth dynamics. Information Sciences, 177(5), 1222-1229.

Chen, Y., \& Yao, Y. (2008). A multiview approach for intelligent data analysis based on data operators. Information Sciences, 178(1), 1-20.

Corchado, E., \& Herrero, Á. (2011). Neural visualization of network traffic data for intrusion detection. Applied Soft Computing, 11(2), 2042-2056.

Corchado, E., \& Fyfe, C. (2003). Connectionist techniques for the identification and suppression of interfering underlying factors. International Journal of Pattern Recognition and Artificial Intelligence, 17(8), 1447-1466.

Corchado, E., Han, Y., \& Fyfe, C. (2003). Structuring global responses of local filters using lateral connections. Journal of Experimental and Theoretical Artificial Intelligence, 15(4), 473-487.

Corchado, E., MacDonald, D., \& Fyfe, C. (2004). Maximum and Minimum Likelihood Hebbian Learning for exploratory projection pursuit. Data Mining and Knowledge Discovery, 8(3), 203-225.

Transparency International (2008). Corruption Perceptions Index. <www.transparency.org > (Retrieved 19.11.2008).

Cuervo-Cazurra, A. (2006). Who cares about corruption? Journal of International Business Studies, 37(6), 807-822.

Cuervo-Cazurra, A. (2008). The effectiveness of laws against bribery abroad. Journal of International Business Studies, 39(4), 634-651.

Jiménez, A., Durán, J. J., \& y De la Fuente, J. M. (2011). El riesgo político como determinante de la estrategia de localización de las empresas multinacionales españolas. Revista Europea de Dirección y Economía de la Empresa, 20(1), $123-142$.

Demartines, P. (1994). Analyze de données par réseaux de neurones auto-organizés. Institut National Polytechnique de Grenoble.

Demartines, P., \& Herault, J. (1997). Curvilinear component analysis: A selforganizing neural network for nonlinear mapping of data sets. IEEE Transactions on Neural Networks, 8(1), 148-154.

Durán, J. J. (2001). Estrategia y economía de la empresa multinacional. Madrid: Pirámide.

Durán, J. J., De la Fuente, J. M., \& Jiménez, A. (2008). Political risk as a determinant of investment by Spanish multinational firms in Europe. Is there an east-west structure? (Working Paper). Paper presented at the 34th EIBA Conference.

Elbashir, M. Z., Collier, P. A., \& Davern, M. J. (2008). Measuring the effects of business intelligence systems: The relationship between business process and organizational performance. International Journal of Accounting Information Systems, 9(3), 135-153.

Feinberg, S. E., \& Gupta, A. K. (2009). MNC subsidiaries and country risk: Internalization as a safeguard against weak external institutions. The Academy of Management Journal (AMJ), 52(2), 381-399.

Földiák, P. (1992). Models of sensory coding. PhD thesis, University of Cambridge.

Friedman, J. H., \& Tukey, J. W. (1974). A projection pursuit algorithm for exploratory data-analysis. IEEE Transactions on Computers, 23(9), 881-890.

Fyfe, C., \& Corchado, E. (2002). Maximum likelihood Hebbian rules. Paper presented at the 10th European symposium on artificial neural networks (ESANN 2002).

Galan, J. I., Gonzalez-Benito, J., \& Zuñiga-Vincente, J. A. (2007). Factors determining the location decisions of Spanish MNEs: An analysis based on the investment development path. Journal of International Business Studies, 38(6), 975-997.

García-Canal, E., \& Guillén, M. F. (2008). Risk and the strategy of foreign location choice in regulated industries. Strategic Management Journal, 29(10), 1097-1115.

Hannula, M., \& Pirttimäki, V. (2003). Business intelligence empirical study on the top 50 Finnish companies. Journal of American Academy of Business, 2(2), 593-601.

Hashmi, M. A., \& Guvenli, T. (1992). Importance of political risk assessment function in US multinational corporations. Global Finance Journal, 3(2), 137-144.

Henisz, W. J. (1998). The institutional environment for international investment. University of California: Hass School of Business.

Henisz, W. J. (2003). The power of the Buckley and Casson Thesis: The ability to manage institutional idiosyncrasies. Journal of International Business Studies, 34(2), 173-184.
Henisz, W. J., \& Zelner, B. A. (2001). The institutional environment for telecommunications investment. Journal of Economics and Management Strategy, 10(1), 123-147.

Henisz, W. J., \& Zelner, B. A. (2002). Interest groups. Mimeo: Institutional Structures and Electricity Investment.

Herrero, Á. et al. (2009). Neural projection techniques for the visual inspection of network traffic. Neurocomputing, 72(16-18), 3649-3658.

Herrero, Á. et al. (2010). DIPKIP: A connectionist knowledge management system to identify knowledge deficits in practical cases. Computational Intelligence, 26(1), 26-56.

Hillman, A. J., \& Hitt, M. A. (1999). Corporate political strategy formulation: A model of approach, participation, and strategy decisions. The Academy of Management Review, 24(4), 825-842.

Holburn, G. L. F. (2001). Regulatory institutions and firm strategy: Theory and evidence from the electric power industry. Berkeley: University of California.

Hotelling, H. (1933). Analysis of a complex of statistical variables into principal components. Journal of Education Psychology, 24, 417-444.

Heritage Foundation (2005). Index of Economic Freedom. <www.heritage.org> (Retrieved 19.11.2008).

Juliana, Y., \& Heather, M. (2005). Comparison of country risk models: Hybrid neural networks, logit models, discriminant analysis and cluster techniques. Expert Systems with Applications, 28(1), 137-148.

Kapuria-Foreman, V. (2007). Economic freedom and foreign direct investment in developing countries. The Journal of Developing Areas, 41(1), 143-154.

Kobrin, S. J. (1979). Political risk - review and reconsideration. Journal of International Business Studies, 10(1), 67-80.

Kohonen, T. (1990). The self-organizing map. IEEE, 78(9), 1464-1480

Kohonen, T. (1997). Self-organizing maps (Vol. 30). Springer-Verlag New York, Inc..

Lall, S. (1996). Learning from the Asian Tigers: Studies in technology and industrial policy. Macmillan.

Li, H., \& Sun, J. (2009). Gaussian case-based reasoning for business failure prediction with empirical data in China. Information Sciences, 179(1-2), 89-108.

Marois, B. (1979). Assessment and management of political risk: Practice of French firms. Annual meeting of the academy of international business. London.

Marois, B. (1981). Comment les Enterprises Francaises Gerent le Risque Politique. Revue Francaise de Gestion, May-August, 4-9.

Mortanges, C. P. d., \& Allers, V. (1996). Political risk assessment: Theory and the experience of Dutch firms. International Business Review, 5(3), 303-318.

Mutinelli, M., \& Piscitello, L. (1997). Differences in the strategic orientation of Italian MNEs in Central and Eastern Europe. The influence of firm-specific factors. International Business Review, 6(2), 185-205.

Spanish Ministry of Industry, Tourism and Commerce (2009). Network of Economic and Commercial Spanish Offices Abroad. <http://www.oficinascomerciales.es> (Retrieved 28.11.2008).

Noordin, B. A., Harjito, D. A., \& Hazir, A. Y. (2006). Political risk assessment of Malaysian based multinational corporation. Problems and Perspectives in Management, 4(3), 91-99.

Oja, E. (1989). Neural networks, principal components, and subspaces. International Journal of Neural Systems, 1, 61-68.

Parks, T. H. (1996). A Foreign market entry decision model: A comparison of theoretical and actual practices of multinational enterprises. Dissertation Abstracts International, 57(10), 4447.

Patterson, D. W. (1998). Artificial neural networks: Theory and applications. Upper Saddle River, NJ, USA: Prentice-Hall PTR.

Pearson, K. (1901). On lines and planes of closest fit to systems of points in space. Philosophical Magazine, 2(6), 559-572.

Rich, G., \& Mahmoud, E. (1990). Political risk forecasting by Canadian firms. International Journal of Forecasting, 6(1), 89-102.

The Economist Intelligence Unit (2009). Risk Briefing. <http://viewswire.eiu.com/ index.asp?layout=RKAllCountryVW3> (Retrieved 11.04.2009).

Ritter, H., Martinetz, T., \& Schulten, K. (1992). Neural computation and self-organizing maps: An introduction. Addison-Wesley Longman Publishing Co., Inc.

Saini, K. G., \& Bates, P. S. (1984). A survey of the quantitative approaches to country risk analysis. Journal of Banking and Finance, 8(2), 341-356.

Seung, H. S., Socci, N. D., \& Lee, D. (1998). The rectified Gaussian distribution. Advances in Neural Information Processing Systems, 10, 350-356.

Slangen, A. H. L., \& van Tulder, R. J. M. (2009). Cultural distance, political risk, or governance quality? Towards a more accurate conceptualization and measurement of external uncertainty in foreign entry mode research. International Business Review, 18(3), 276-291.

Laboratory of Computer and Information Science. Helsinki University of Technology (2009). SOM Toolbox for Matlab. <http://www.cis.hut.fi/projects/somtoolbox/> (Retrieved 24.06.2009).

Wan, W. P. (2005). Country resource environments, firm capabilities, and corporate diversification strategies. Journal of Management Studies, 42(1), 161-182.

Wei, S.-J. (1997). How taxing is corruption on international investors? Review of Economics and Statistics, 82(1), 1-11.

Wernerfelt, B. (1984). A resource-based view of the firm. Strategic Management Journal, 5(2), 171-180.

Wheeler, D., \& Mody, A. (1992). Institutional investment location decisions, the case of US firms. Journal of International Economics, 33, 57-76. 